OPEN ACCESS

Edited by: Hongbo Chi,

St. Jude Children's Research Hospital, United States

Reviewed by: Xiao-Ping Zhong, Duke University Medical Center, United States Kai Yang, Indiana University - Lafayette, United States

*Correspondence: Jung-Hyun Park parkhy@mail.nih.gov

Specialty section: This article was submitted to T Cell Biology, a section of the journal Frontiers in Immunology

Received: 16 December 2020 Accepted: 27 April 2021 Published: 14 May 2021

Citation:

Won HY, Kim HK, Crossman A, Awasthi P, Gress RE and Park J-H (2021) The Timing and Abundance of IL-2Rß (CD122) Expression Control

Thymic iNKT Cell Generation and NKT1 Subset Differentiation.

Front. Immunol. 12:642856. doi: 10.3389/fimmu.2021.642856

\section{The Timing and Abundance of IL-2R $\beta$ (CD122) Expression Control Thymic iNKT Cell Generation and NKT1 Subset Differentiation}

\author{
Hee Yeun Won ${ }^{1}$, Hye Kyung Kim ${ }^{2}$, Assiatu Crossman ${ }^{1}$, Parirokh Awasthi ${ }^{3}$, \\ Ronald E. Gress ${ }^{2}$ and Jung-Hyun Park ${ }^{1 *}$ \\ ${ }^{1}$ Experimental Immunology Branch, Center for Cancer Research, National Cancer Institute, National Institutes of Health, \\ Bethesda, MD, United States, ${ }^{2}$ Experimental Transplantation and Immunotherapy Branch, Center for Cancer Research, \\ National Cancer Institute, National Institutes of Health, Bethesda, MD, United States, ${ }^{3}$ Laboratory Animal Sciences Program, \\ Leidos Biomedical Research, Inc., Frederick National Laboratory for Cancer Research, Frederick, MD, United States
}

Invariant NKT (iNKT) cells are thymus-generated innate-like T cells, comprised of three distinct subsets with divergent effector functions. The molecular mechanism that drives the lineage trifurcation of immature iNKT cells into the NKT1, NKT2, and NKT17 subsets remains a controversial issue that remains to be resolved. Because cytokine receptor signaling is necessary for iNKT cell generation, cytokines are proposed to contribute to iNKT subset differentiation also. However, the precise roles and requirements of cytokines in these processes are not fully understood. Here, we show that IL-2R $\beta$, a nonredundant component of the $\mathrm{IL}-15$ receptor complex, plays a critical role in both the development and differentiation of thymic iNKT cells. While the induction of IL-2R $\beta$ expression on postselection thymocytes is necessary to drive the generation of $\mathrm{NKT}$ cells, surprisingly, premature IL-2R $\beta$ expression on immature iNKT cells was detrimental to their development. Moreover, while IL-2R $\beta$ is necessary for NKT1 generation, paradoxically, we found that the increased abundance of IL-2R $\beta$ suppressed NKT1 generation without affecting NKT2 and NKT17 cell differentiation. Thus, the timing and abundance of IL-2R $\beta$ expression control iNKT lineage fate and development, thereby establishing cytokine receptor expression as a critical regulator of thymic iNKT cell differentiation.

Keywords: cytokines, IL-2 (interleukin-2), IL-15, Tbet, thymocytes

\section{INTRODUCTION}

Cytokines of the common $\gamma$-chain $(\gamma c)$ family play critical roles in the generation and differentiation of $\mathrm{T}$ cells in the thymus (1-3). Importantly, $\gamma c$ cytokines not only provide prosurvival signals and metabolic cues, but they also specify the lineage commitment of thymocytes and equip developing $\mathrm{T}$ cells with effector function (1). Along these lines, a requirement for intrathymic interleukin-7 (IL-7) in $\mathrm{T}$ cell development is well established, as documented in its role to control the expansion of immature thymocytes and to determine CD8 cytotoxic T cell lineage fate $(2,4)$. IL-4, on the other hand, drives the differentiation of innate-like CD8 T cells (5), whereas IL-2 signaling is critical for 
the generation of Foxp $3^{+} \mathrm{T}$ regulatory (Treg) cells (6). Collectively, $\gamma_{c}$ cytokine signaling is necessary for the development of $\alpha \beta \mathrm{T}$ cells; however, the identity of the required cytokine differs depending on the individual lineages or subsets of $\mathrm{T}$ cells that are generated.

Cytokine signaling is also important for the generation of invariant NKT ( $i \mathrm{NKT}$ ) cells, a population of innate-like $\alpha \beta \mathrm{T}$ cells that are produced in the thymus $(7,8)$. $i$ NKT cells are potent immunoregulatory cells that produce pro-inflammatory cytokines, but they differ from conventional $\alpha \beta$ T cells because they acquire effector function before antigen encounter and activation $(7,8)$. Depending on the cytokines they produce and the transcription factors they express, $i$ NKT cells can be categorized into three distinct subsets $(9,10)$. $i$ NKT cells that are T-bet ${ }^{+}$and produce IFN $\gamma$ correspond to NKT1 cells. IL-17producing ROR $\gamma \mathrm{t}^{+} i \mathrm{NKT}$ cells, on the other hand, are NKT17 cells, and IL-4-producing PLZF ${ }^{\text {hi }}$ iNKT cells are NKT2 cells (9, 10). The molecular mechanisms that drive $i \mathrm{NKT}$ subset differentiation are not fully mapped. However, cytokines have been implicated in determining $i$ NKT subset specification. Thus, IL-15 promotes NKT1 cell development (11), TGF- $\beta$ induces NKT17 cell generation (12), and IL-25 produced by thymic tuft cells possibly drives the differentiation of NKT2 cells (13). Consequently, cytokines can specify the differentiation of $i \mathrm{NKT}$ cells in the thymus. However, it remains unclear why some $i \mathrm{NKT}$ precursors would respond to IL-15 and become NKT1 cells, whereas other precursors are refractory to IL-15 and choose other lineage fates. This problem is further compounded by all $i$ NKT cells expressing the same semi-invariant TCR so that differences in the TCR repertoire are unlikely to play a significant role in subset differentiation. Instead, we consider it likely that differences in the timing or abundance of cytokine receptors could determine the responsiveness to subsetspecifying cytokines.

Among $i$ NKT cells, the NKT1 subset is of particular interest because it comprises most of the thymic $i$ NKT cells in C57BL/6 mice. NKT1 cells are also important because they produce copious amounts of IFN $\gamma$, which affects T cell lineage differentiation and promotes the terminal maturation of thymic epithelial cells $(14,15)$. NKT1 cells require IL-15 for their generation, whereby intrathymic IL-15 is primarily provided by medullary thymic epithelial cells $(16,17)$. IL-15 is a $\gamma_{c}$ family cytokine that signals through $\gamma_{c}$ and IL-2R $\beta$ (3). Consistent with its requirement for IL-15 signaling, IL-2R $\beta$ deficiency was previously shown to dramatically impair the generation of $i$ NKT cells in the thymus $(18,19)$. However, it remains unclear whether the lack of IL-2R $\beta$ would specifically impede the generation of NKT1 cells or the differentiation of all thymic $i$ NKT subsets. Moreover, if IL-2R $\beta$ is necessary for NKT1 cell differentiation, we wished to assess whether IL-2R $\beta$ would be sufficient to drive NKT1 cell generation. If such were the case, we expected that the forced expression of IL-2R $\beta$ would impose the NKT1 subset fate onto all developing $i$ NKT cells, resulting in a heavily skewed $i$ NKT subset composition where NKT1 cells would be overrepresented and NKT2 and NKT17 cells would be underrepresented. To this end, we examined the generation and differentiation of $i$ NKT cells in IL- $2 \mathrm{R} \beta^{\mathrm{Tg}}$ mice in both the
C57BL/ 6 and $\mathrm{BALB} / \mathrm{c}$ backgrounds, and further generated mice with conditional deletion of IL-2R $\beta$ upon $i$ NKT lineage commitment. Here, we show that not only the expression itself but also the carefully curated timing of IL- $2 \mathrm{R} \beta$ induction is important for the generation and subset differentiation of $i \mathrm{NKT}$ cells. Collectively, these results unveil previously unappreciated roles and requirements of the cytokine receptor IL-2R $\beta$ in controlling thymic $i$ NKT cell development.

\section{MATERIALS AND METHODS}

\section{Mice}

$\mathrm{C} 57 \mathrm{BL} / 6 \mathrm{NCrl}(\mathrm{C} 57 \mathrm{BL} / 6)$ and BALB/cAnNCrl (BALB/c) mice were obtained from the Charles River Laboratories (Frederick, MD). $\mathrm{IL}-2 \mathrm{R} \beta^{\mathrm{Tg}}$ mice were generated in house as previously described (20). IL-2R $\beta$-deficient mice (Il2rb $\left.{ }^{-/-}\right)$and IL-2R $\beta$-floxed mice $\left(I l 2 r b^{\mathrm{fl} / \mathrm{fl}}\right)$ were obtained from the Jackson Laboratories $(21,22)$. PLZF ${ }^{\text {Cre }}$ transgenic mice were kindly provided by Dr. D. Sant'Angelo (Rutgers University, NJ) (23). CA-STAT5 ${ }^{\text {Tg }}$ mice were a kind gift from by Dr. M. A. Farrar (U. Minnesota, MN) (24). T-bet-ZsGreen reporter transgenic mice $\left(\mathrm{TBGR}^{\mathrm{Tg}}\right.$ ) on $\mathrm{C} 57 \mathrm{BL} / 6$ background were a kind gift from Dr. Jinfang Zhu (NIAID, NIH) (25), and these mice were backcrossed to BALB/cAnNCrl for at least 6 generations before analysis. All experimental mice were analyzed between 6 and 12 weeks of age, except for Il2rb ${ }^{-1-}$ and their littermate controls, which were analyzed between 4 and 6 weeks of age. All mice were cared for in accordance with $\mathrm{NIH}$ guidelines. Animal experiments were approved by the NCI Animal Care and Use Committee.

\section{Flow Cytometry}

Single-cell suspensions were prepared from the indicated tissues and stained with fluorescence-conjugated antibodies as previously described (26). The data were acquired using LSR Fortessa or LSRII flow cytometers (BD Biosciences) and were analyzed using software platforms developed by the EIB Flow Cytometry Facility, CCR, NCI, NIH. Live cells were gated by forward scatter exclusion of dead cells stained with propidium iodide. The following antibodies were used for staining: HSA (M1/69), T-bet (4B10), Foxp3 (FJK-16s), ROR $\gamma t$ (AKFJS-9) and isotype control antibodies, all from eBioscience; CD4 (GK1.5 and RM4.5), CD8 $\alpha$ (53-6-7), CD69 (H1.2F3), TCR $\beta$ (H57-597) and IL2R $\beta$ (TM- $\beta 1$ ) from BD Biosciences; CD44 (IM7), NK1.1 (PK136), IL2R $\alpha$ (PC61), CCR7 (4B12) and PLZF (9E12) from BioLegend. Fluorochrome-conjugated CD1d tetramers loaded with PBS-57 (CD1dTet) and unloaded controls were obtained from the NIH tetramer facility (Emory University, Atlanta, GA). Intracellular Foxp3, PLZF, ROR $\gamma$ t, and T-bet proteins were detected using a Foxp3 staining kit according to the manufacturer's instructions (eBioscience Thermo Fisher).

\section{iNKT Subset Identification by Transcription Factors}

To identify the subset composition of $i$ NKT cells, total thymocytes were first stained with PBS-57-loaded mouse CD1d tetramers, fixed, permeabilized and then stained for nuclear 
transcription factors. Briefly, thymocytes were stained with fluorochrome-conjugated CD1d tetramers in FACS buffer (0.5\% BSA, $0.1 \%$ sodium azide in $\mathrm{Ca}^{2+}$ and $\mathrm{Mg}^{2+}$-free HBSS) for 20 minutes at $4^{\circ} \mathrm{C}$. Without removing the tetramer reagents, the cells were incubated for an additional $30 \mathrm{~min}$ at $4^{\circ} \mathrm{C}$ with antibodies for surface markers. Excess reagents were then washed out with FACS buffer, and the cells were resuspended in a 1:3 mixture of concentrate/diluent working solution of the Foxp3 Transcription Factor Staining Buffer kit (eBioscience Thermo Fisher), followed by incubation at room temperature for 20 minutes. Next, the cells were washed twice with $1 \times$ permeabilization buffer (eBioscience Thermo Fisher) before adding antibodies for transcription factors, specifically antibodies against PLZF, ROR $\gamma$ t and T-bet. The cells were incubated at room temperature for 1 hour before washing out excess reagents with FACS buffer and analysis by flow cytometry.

\section{Alzet Osmotic Pump Installation}

Recombinant mouse IL-15 (Peprotech) dissolved in PBS was administered into IL-2R $\beta^{\mathrm{Tg}} \mathrm{BALB} / \mathrm{c}$ mice using Alzet osmotic pumps (Durect) following the manufacturer's instruction. The pumps (model 1002) were set to release IL-15 at a rate of $3 \mu \mathrm{g}$ of recombinant IL-15 per 24 hours.

\section{Statistical Analysis}

The data were shown as the means \pm SEM. Statistical significance was determined by unpaired two-tailed Student's $t$-test. $P$ values of less than 0.05 were considered significant. ${ }^{\star} P<0.05,{ }^{\star \star} P<0.01$, ${ }^{\star * *} P<0.001$. All statistical analysis was performed using GraphPad Prism 7 software (GraphPad software).

\section{RESULTS}

\section{IL-2R $\beta$ Expression Is Induced Upon Thymic iNKT Cell Differentiation}

To understand the role of IL-2R $\beta$ in thymic $i$ NKT cell generation, we first examined IL-2R $\beta$ expression on $i$ NKT cells in the context of $\alpha \beta \mathrm{T}$ cell development in the thymus. The process of thymocyte positive selection and maturation can be visualized using the combination of the two surface markers CD69 and CCR7 which identifies 5 distinct developmental stages, progressing from stage I to stage V (Figure 1A, top) (27). TCR engagement of immature thymocytes (stage I) induces the expression CD69 (stage II) followed by the upregulation of the chemokine receptor CCR7, so that $\mathrm{CD} 9^{+} \mathrm{CCR} 7^{\text {int }}$ cells (stage III) correspond to thymocytes undergoing positive selection and lineage commitment. Stage IV and V cells, on the other hand, correspond to postselection thymocytes. We found that $i \mathrm{NKT}$ cells, as identified by PBS-57-loaded CD1d tetramers $\left(\mathrm{CD} 1 \mathrm{dTet}^{+}\right)$, arise as early as in stage $\mathrm{I}$, and that they were then prominent in stage II (Figure 1A, bottom). Importantly, stage I $i$ NKT cells expressed both the cytokine receptor $\gamma \mathrm{c}$ and IL-2R $\beta$ (Figure 1B and Supplementary Figure 1), indicating that the induction of IL-2R $\beta$ is one of the earliest events in $i \mathrm{NKT}$ cell development. Indeed, such kinetics of IL-2R $\beta$ expression differed substantially from that of CD1dTet-negative conventional $\alpha \beta \mathrm{T}$ cells, which remained mostly absent for IL$2 \mathrm{R} \beta$ expression throughout their development (Figure 1B and Supplementary Figure 2).

To further align IL-2R $\beta$ expression with the selection and maturation of $i \mathrm{NKT}$ cells, we next assessed surface IL-2R $\beta$ expression in developmental stages of thymic $i$ NKT cells. CD44-negative $\mathrm{HSA}^{\text {hi }}$ thymocytes that bind PBS-57-loaded CD1d tetramers correspond to preselection $i \mathrm{NKT}$ cells, and they are usually referred to as stage 0 (ST0) $i$ NKT cells (28). IL-2R $\beta$ was mostly absent on ST0 $i$ NKT cells but was induced following differentiation into $\mathrm{HSA}^{\text {lo }}$ mature $i \mathrm{NKT}$ cells (Figure 1C and Supplementary Figure 1B). Thymic differentiation of HSA $^{\text {lo }} i$ NKT cells proceeds along a well-characterized pathway that is marked by the expression of CD44 and NK1.1, whereby $\mathrm{CD} 44^{-} \mathrm{NK} 1.1^{-}$cells correspond to stage 1 (ST1), followed by $\mathrm{CD} 44^{+} \mathrm{NK} 1.1^{-}$cells that are stage 2 (ST2), and terminally differentiate into $\mathrm{CD} 44^{+} \mathrm{NK} 1.1^{+}$stage 3 cells (ST3) (28). Interestingly, IL-2R $\beta$ was expressed at low levels on ST1 and ST2 cells but highly expressed on ST3 $i$ NKT cells (Figure 1C and Supplementary Figure 1B). Thus, all mature thymic $i$ NKT cells express IL-2R $\beta$ to a certain degree, but the amount of surface IL$2 \mathrm{R} \beta$ proteins substantially increases with maturation.

Mature $i$ NKT cells are also categorized into 3 distinct subsets, namely NKT1, NKT2, and NKT17 cells, based on their transcription factor expression profiles (10). Differential expression of the transcription factors PLZF versus ROR $\gamma$ t can visualize these three subsets, which we utilized to assess IL-2R $\beta$ expression on individual thymic $i$ NKT subsets (Figure 1D). Consistent with previous observations (10), IL-2R $\beta$ was highly induced on NKT1 cells and minimally expressed on PLZF $^{\text {hi }}$ ROR $\gamma t^{\text {neg }}$ NKT2 and PLZF ${ }^{\text {int }}{\text { ROR } \gamma t^{+}}^{+}$NKT17 cells (Figure 1D). Altogether, these results demonstrated that IL-2R $\beta$ is highly upregulated on terminally differentiated ST3 $i$ NKT cells and that such IL-2R $\beta^{+} i \mathrm{NKT}$ cells correspond to NKT1 cells.

\section{Conditional Deletion of IL-2R $\beta$ in PLZF $^{+}$Thymocytes}

Having established that IL-2R $\beta$ expression is associated with $i$ NKT cell maturation, we next wished to examine whether IL$2 \mathrm{R} \beta$ would be also required for the development and differentiation of $i$ NKT cells. To this end, we aimed to set up an experimental system where IL-2R $\beta$ would be selectively deleted in $i$ NKT cells. The zinc finger transcription factor PLZF is expressed in $i$ NKT cells but absent in conventional $\mathrm{T}$ cells $(29,30)$. Thus, we bred PLZF-Cre transgenic mice $\left(\mathrm{PLZF}^{\mathrm{Cre}}\right)$ with $I l 2 r b^{\mathrm{fl} / \mathrm{fl}}$ mice $(21,23)$ to generate $I l 2 r b^{\mathrm{fl} / \mathrm{fl}}$ $\mathrm{PLZF}^{\mathrm{Cre}}$ mice and to specifically delete IL-2R $\beta$ in $i \mathrm{NKT}$ cells. In such $I l 2 r b^{\mathrm{fl} / \mathrm{fl}} \mathrm{PLZF}{ }^{\mathrm{Cre}}$ mice, the thymic development of conventional $\mathrm{T}$ cells was unaffected (Supplementary Figure 3A). Both TCR $\beta$ expression and the CD4 versus CD8 profiles of $I l 2 r b^{\mathrm{fl} / \mathrm{fl}} \mathrm{PLZF}{ }^{\mathrm{Cre}}$ thymocytes remained comparable to those of littermate $I l 2 r b^{\mathrm{fl} / \mathrm{fl}} \mathrm{PLZF}^{\mathrm{WT}}$ thymocytes (Supplementary Figure 3A). Contrary to our expectation, however, the frequency and number of thymic $i \mathrm{NKT}$ cells also remained unaltered in $I l 2 r b^{\mathrm{fl} / \mathrm{fl}} \mathrm{PLZF}{ }^{\mathrm{Cre}}$ mice (Figure 2A). 


\section{A}

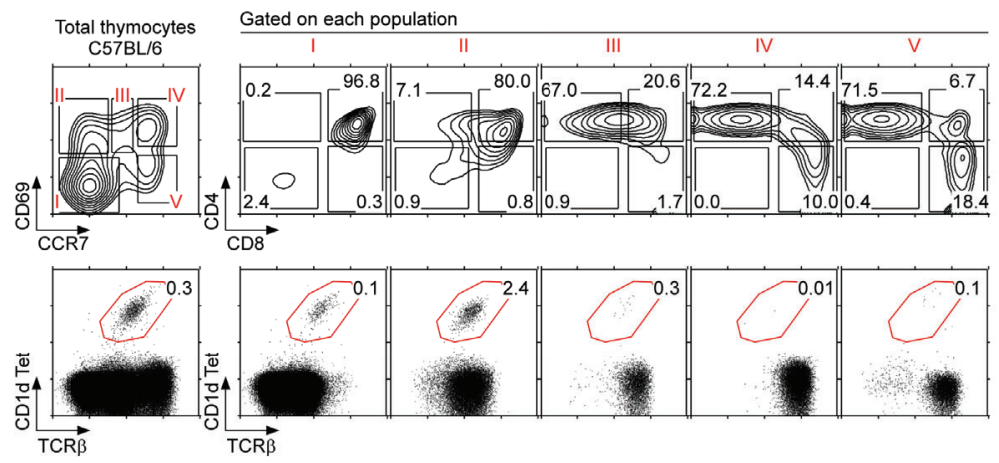

B
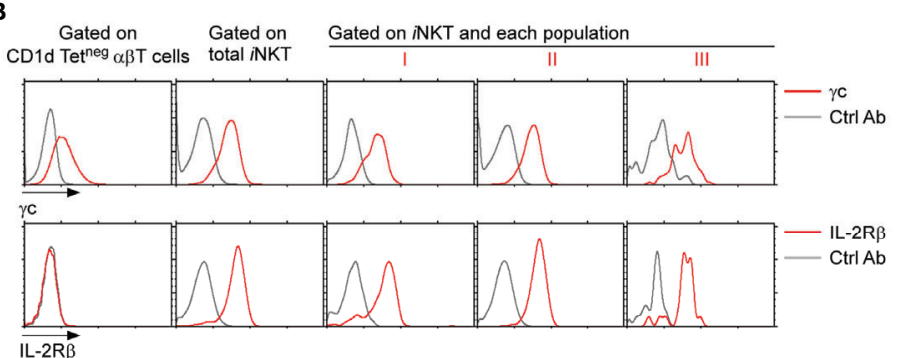

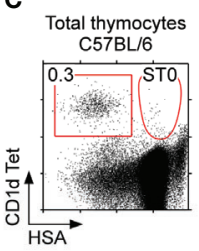

Gated on HSAlo CD1d Tet ${ }^{+}$

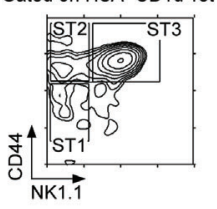

Gated on each stage
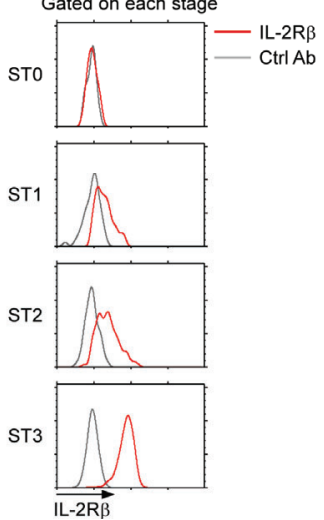

D Total thymocytes

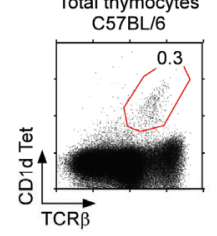

Gated on TCR $\beta^{+} \mathrm{CD} 1 \mathrm{~d} \mathrm{Tet}^{+}$
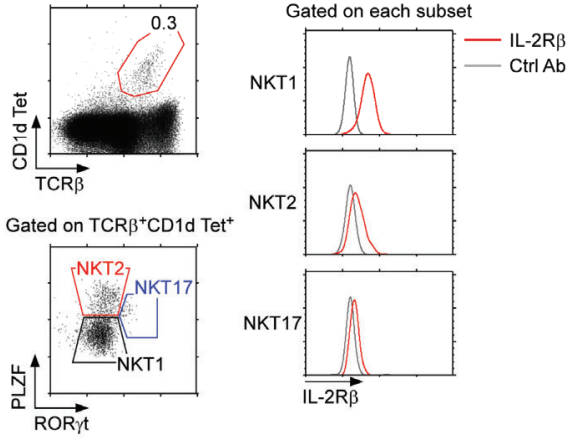

NKT
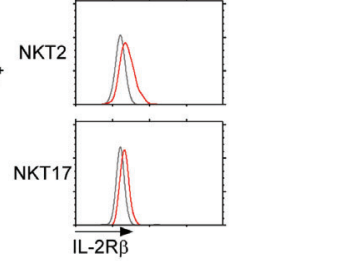

FIGURE 1 | IL-2R 3 expression on thymic iNKT cells (A) C57BL/6 thymocytes were assessed for surface CD69 and CCR7 staining, which visualizes 5 distinct stages of differentiation (i.e., stages I-V), whereby thymocytes undergoing positive selection correspond to population III (top). iNKT cells were identified by PBS57loaded CD1d tetramer (CD1dTet) staining among the 5 stages defined by CD69 and CCR7 (bottom). The results are representative of 5 independent experiments with a total of 5 WT C57BL/6 mice. (B) Surface cytokine receptor expression on thymic iNKT cell populations. iNKT cells in populations I, II, and III were assessed for $\gamma c$ and IL-2R $\beta$ expression (red lines). Isotype control antibody staining are shown as gray lines. The results are representative of 3 independent experiments. (C) IL$2 \mathrm{R} \beta$ expression during iNKT cell differentiation. Thymic iNKT cells were divided into immature ST0 and mature stage 1-3 cells based on HSA expression (left, top). The abundance of IL-2R $\beta$ was then assessed on ST0 (HSA $\left.{ }^{\text {hi CD44 }}{ }^{-}\right)$, ST1 (CD44 $\left.4^{-} \mathrm{NK} 1.1^{-}\right)$, ST2 (CD44 $\left.{ }^{+} \mathrm{NK} 1.1^{-}\right)$, and ST3 $\left(\mathrm{CD} 44^{+} \mathrm{NK} 1.1^{+}\right)$iNKT cells (left, bottom). Histograms show surface IL-2R $\beta$ expression for each subset (red line). Isotype control antibody staining are shown as gray lines. The results are representative of 5 independent experiments. (D) IL-2Rß expression in thymic iNKT subsets. iNKT cells were assessed for intracellular PLZF and ROR 7 t expression to identify NKT1, NKT2, and NK17 cells (left). Each iNKT subset was assessed for IL-2R $\beta$ expression (right, red lines). Isotype control antibody staining are shown as gray lines. The results are representative of 3 independent experiments.

To understand these results, we considered two possibilities. Firstly, IL-2R $\beta$ expression in the thymus could be dispensable for $i$ NKT cell generation. Alternatively, the PLZF-Cre-mediated deletion of IL-2R $\beta$ could be incomplete. In the latter case, the variegated expression of the PLZF-Cre or inefficient excision of the floxed allele could result in the retention of IL-2R $\beta$ expression. To discriminate these possibilities, it would be necessary to monitor the deletion efficiency of IL-2R $\beta$ in $I l 2 r b^{\mathrm{fl} / 1 \mathrm{l}} \mathrm{PLZF} \mathrm{F}^{\mathrm{Cre}}$ mice. Notably, the Il2rb-floxed allele $\left(I l 2 r b^{\mathrm{fl}}\right)$ is engineered to induce the expression of Green Fluorescent Proteins (GFP) upon IL-2R $\beta$ deletion (21), permitting the identification of $i$ NKT cells that have deleted IL-2R $\beta$. Employing this feature, we next analyzed the efficiency of IL$2 \mathrm{R} \beta$ deletion by assessing GFP expression. Among $\mathrm{HSA}^{\text {hi }}$ immature $i$ NKT cells (ST0), GFP was only found in a very small fraction of $i$ NKT cells (Figure 2B, top histogram). Among HSA $^{\text {lo }} i$ NKT cells, however, a large fraction of cells turned out to be $\mathrm{GFP}^{+}$, reporting the successful deletion of the $I l 2 r b^{\mathrm{fl}}$ 
A

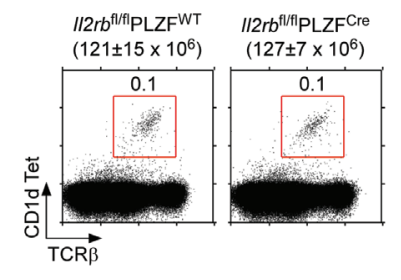

iNKT cells

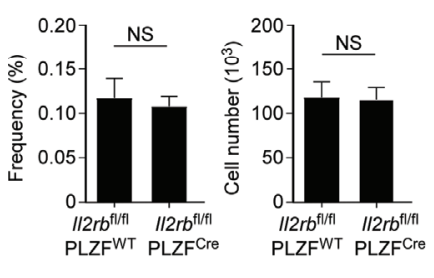

B
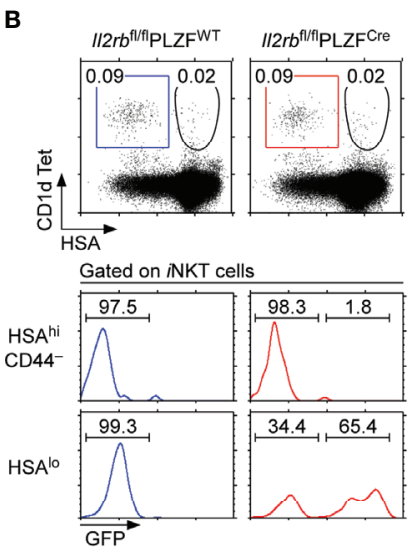

C

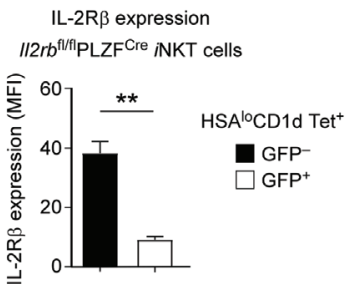

D

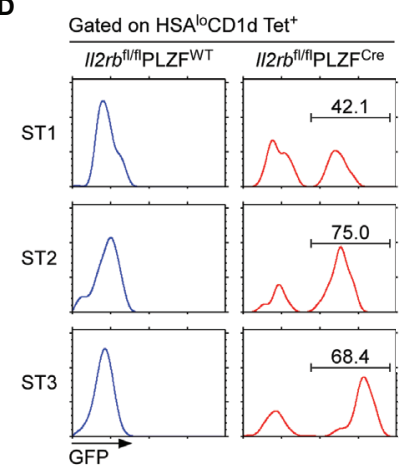

E
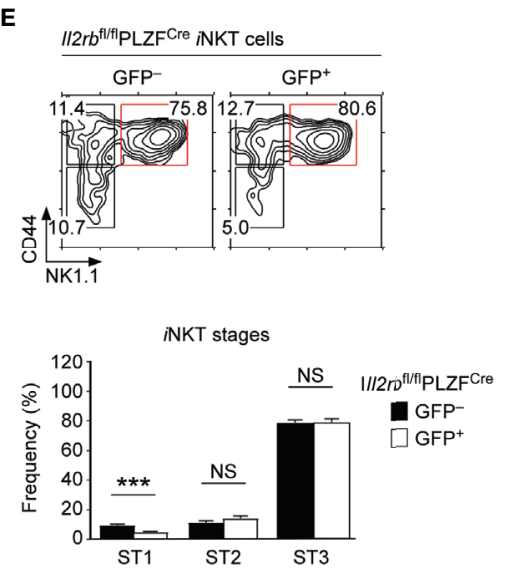

$\mathbf{F}$

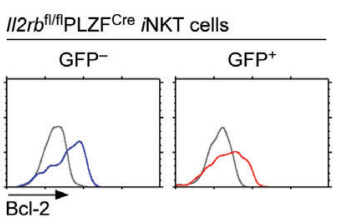

$1 / 2 \mathrm{rb}^{\mathrm{f} / \mathrm{fl} \mathrm{PLZF}}{ }^{\mathrm{Cre}}$ iNKT cells

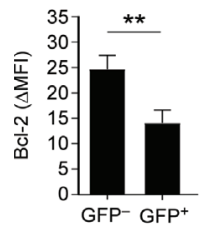

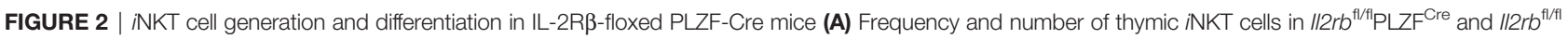
littermate control mice. The dot plots show thymic iNKT cells as identified by CD1dTet versus TCR $\beta$ staining (top). The bar graphs show the frequencies and numbers of iNKT cells from the indicated mice (bottom). The dot plot is representative, and the bar graphs are a summary of 4 independent experiments with a total

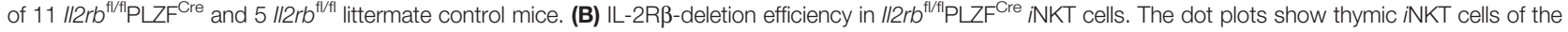

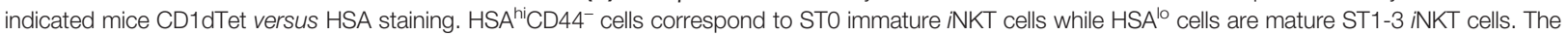
histograms show GFP expression among the indicated population of thymic iNKT cells. (C) IL-2R $\beta$ expression in GFP+ and GFP-negative mature iNKT cells of II2rb fl/fl

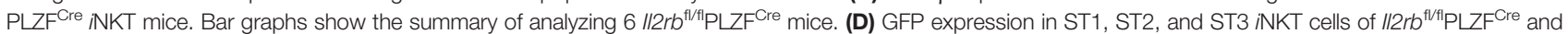
littermate control thymocytes. The data are representative of 4 independent experiments. (E) Thymic iNKT cell differentiation in $/ I 2 r b^{\mathrm{ff} / f} \mathrm{PLZF} \mathrm{F}^{\mathrm{Cre}}$ mice. $\mathrm{NKKT}_{\text {cells }}$ were stained for CD44 and NK1.1 to identify ST1, ST2, and ST3 cells as shown in the contour plots (top). The bar graph shows the frequencies of ST1, ST2, and ST3 cells in $\mathrm{GFP}^{+}$and GFP- thymic $i N K T$ cells of $\| / 2 \mathrm{rb}^{\mathrm{fl} / \mathrm{fl}} \mathrm{PLZF} \mathrm{F}^{\mathrm{Cre}}$ mice (bottom). Results show the summary of 6 independent experiments with a total of $14 \| / 2 \mathrm{rb}^{\mathrm{fl} / \mathrm{fl}} \mathrm{PLZF} \mathrm{Fre}^{\mathrm{Cr}}$ mice. (F) Bcl-2 expression in $\mathrm{GFP}^{+}$and $\mathrm{GFP}^{-}$iNKT cells of $1 / 2 \mathrm{rb}^{\mathrm{fl} / \mathrm{fl}} \mathrm{PLZF}^{\mathrm{Cre}}$ thymocytes. Histograms are representative (left), and the bar graph (right) shows the summary of 3 independent experiments with a total of $8 \| / 2 r^{f / / f l} P L Z F^{C r e}$ mice. ${ }^{\star \star} P<0.01$; ${ }^{\star \star *} P<0.001$. NS, Not Significant.

allele in mature $i$ NKT cells (Figure 2B, bottom histogram, and Supplementary Figure 3B). Assessing the surface IL-2R $\beta$ expression on $\mathrm{GFP}^{+}$and GFP-negative mature $i \mathrm{NKT}$ cells showed a substantial loss of surface IL-2R $\beta$ on $\mathrm{GFP}^{+}$cells (Figure 2C and Supplementary Figure 3C). Thus, $\mathrm{GFP}^{+}$cells correspond to $i \mathrm{NKT}$ cells that have terminated IL-2R $\beta$ expression. Importantly, the frequencies of such $\mathrm{GFP}^{+} i \mathrm{NKT}$ cells increased upon their further differentiation into ST1, ST2, and ST3 $i$ NKT cells (Figure 2D). These results suggested that $\mathrm{PLZF}^{\mathrm{Cre}}$ - mediated deletion of IL-2R $\beta$ is initiated in ST0 cells but not accomplished until later stages of $i$ NKT cell development. Because of this delayed deletion, significant amounts of surface 
IL-2R $\beta$ remained on $\mathrm{GFP}^{+} i \mathrm{NKT}$ cells which could provide residual IL-2R signaling (Figure 2C). Along these lines, we noted that a significant fraction of $\mathrm{HSA}^{\mathrm{lo}}$ mature $i \mathrm{NKT}$ cells remained GFP-negative and fully expressed IL-2R $\beta$ (Figure 2B bottom). Such inefficient deletion could explain why we did not find significant differences in the frequency and number of thymic $i \mathrm{NKT}$ cells between $I l 2 r b^{\mathrm{fl} / \mathrm{fl}} \mathrm{PLZF}^{\mathrm{Cre}}$ and littermate control mice (Figure 2A). We also did not find any significant changes in the ST1-ST3 distribution of $\mathrm{GFP}^{+} i \mathrm{NKT}$ cells which expressed dramatically lower amounts of IL-2R $\beta$ compared to GFP-negative $i$ NKT cells (Figure 2E). We also did not find differences in the ST1-3 distribution of $I l 2 r b^{\mathrm{fl} / \mathrm{fl}} \mathrm{PLZF}^{\mathrm{Cre}}$ mice compared to $I l 2 r b^{\mathrm{fl} / \mathrm{fl}} \mathrm{PLZF}{ }^{\mathrm{WT}}$ littermates that express normal amounts of IL-2R $\beta$ (Supplementary Figure 3D). Along these lines, the thymic $i$ NKT subset composition and the frequency of T-bet ${ }^{+} i$ NKT cells which correspond to ST3 cells were virtually unaltered in $I l 2 r b^{\mathrm{fl} / \mathrm{fl}} \mathrm{PLZF}^{\mathrm{Cre}}$ mice (Supplementary Figures 4A, B). On the other hand, the protein abundance of Bcl-2, a direct downstream molecule of IL-2R $\beta$ signaling (31), was markedly diminished (Figure 2F), indicating that the lack of IL-2R $\beta$ had physiological consequences for $i$ NKT cells. Nonetheless, the survival of $\mathrm{GFP}^{+}$thymic iNKT cells remained unaffected, because $\mathrm{Bcl}-\mathrm{xL}$ and not $\mathrm{Bcl}-2$ provides pro-survival signals for $i$ NKT cells (11). In agreement the frequency and number as well as the subset composition of iNKT cells in the spleen did not differ between $I l 2 r b^{\mathrm{fl} / \mathrm{fl}} \mathrm{PLZF}^{\mathrm{Cre}}$ and $I l 2 r b^{\mathrm{fl} / \mathrm{fl}} \mathrm{PLZF}^{\mathrm{WT}}$ mice (Supplementary Figure 4C). Collectively, the undisturbed differentiation of $\mathrm{GFP}^{+} i \mathrm{NKT}$ cells in $I l 2 r b^{\mathrm{fl} / \mathrm{fl}} \mathrm{PLZF}^{\mathrm{Cre}}$ mice suggested that the late-stage deletion of IL-2R $\beta$ is not detrimental for the ST1 to ST3 $i$ NKT cell maturation.

\section{IL-2R $\beta$ Is Critical for the Generation of Thymic iNKT Cells}

To further delineate the role of IL-2R $\beta$ in the generation and differentiation of $i \mathrm{NKT}$ cells, we next analyzed the development and subset composition of thymic $i \mathrm{NKT}$ cells in germline IL2R $\beta$-deficient $\left(I l 2 r b^{-1-}\right.$ ) mice (22). In $I l 2 r b^{-/-}$mice, all thymocytes - including ST0 immature $i$ NKT cells - are devoid of IL-2R $\beta$. Thus, an IL-2R $\beta$ requirement for $i$ NKT cells can be assessed starting at the earliest precursor stages of $i \mathrm{NKT}$ cell development. Notably, Il2rb $\mathrm{rb}^{-/-}$mice are autoimmune because of the impaired generation of immunosuppressive Foxp $3^{+}$Treg cells that require IL-2 signaling for their maturation $(32,33)$. Consequently, we analyzed $I l 2 r b^{-/-}$mice before 6 weeks of age to avoid the potential skewing of $i \mathrm{NKT}$ cell differentiation due to autoimmunity. We confirmed that the thymus of $I l 2 r b^{-/-}$mice at that age did not show an overtly activated phenotype, and that $\mathrm{T}$ cell development remained comparable to that of WT littermate mice (Supplementary Figure 5A). We further confirmed the lack of in vivo IL-2R $\beta$ signaling in $I l 2 r b^{-1-}$ mice by their absence of mature $\mathrm{CD} 25^{+} \mathrm{Foxp}^{+}$Treg cells which require IL-2R signaling for their generation (Supplementary Figure 5B) (32, 33). Consistent with previous reports $(18,19)$, we confirmed a dramatic reduction in the frequency and number of thymic $i \mathrm{NKT}$ cells of $\mathrm{Il}_{2} \mathrm{rb}^{-1-}$ mice compared with those of WT littermate mice (Figure 3A). Notably, the loss was specific for $i$ NKT cells and did not affect conventional $\alpha \beta$ T cells, resulting in a dramatically decreased ratio of $i$ NKT cells over $\alpha \beta \mathrm{T}$ cells (Supplementary Figure 5C).

Most thymic $i \mathrm{NKT}$ cells in $\mathrm{C} 57 \mathrm{BL} / 6$ background mice correspond to ST3 cells. Therefore, we expected that IL-2R $\beta$ deficiency would selectively affect the differentiation of ST3 $i \mathrm{NKT}$ cells. Indeed, Il2 $r b^{-1-}$ thymic $i \mathrm{NKT}$ cells were developmentally arrested, resulting in the accumulation of ST1/ST2 $i$ NKT cells and in a substantial decrease in ST3 $i$ NKT cells (Figure 3B). We further found that the fraction of NKT1 cells was significantly diminished among $I l 2 r b^{-/-} i \mathrm{NKT}$ cells, which in turn resulted in the relative overrepresentation of NKT2 and NKT17 cells (Figure 3C). The $i$ NKT cell number for each subset, however, were significantly reduced (Figure 3C), which was consistent with the dramatic decrease in total $i \mathrm{NKT}$ cell numbers in $I l 2 r b^{-/-}$mice (Figure 3A). Collectively, these results from $\mathrm{Il} 2 \mathrm{rb}^{-/-}$mice documented a major role for the cytokine receptor IL-2R $\beta$ in the generation, but also in the subset differentiation of thymic $i$ NKT cells.

\section{Forced Expression of IL-2R $\beta$ Suppresses iNKT Cell Development in the Thymus}

Because IL-2R $\beta$ is important for NKT1 cell generation (Figure 3C), we next asked whether IL-2R $\beta$ would be also sufficient to impose NKT1 lineage fate during $i$ NKT cell development. To this end, we assessed $i$ NKT cell development in IL-2R $\beta$-transgenic mice (IL-2R $\beta^{\mathrm{Tg}}$ ) that overexpress mouse IL-2R $\beta$ under the control of human CD2 promoter/enhancer elements $(20,34)$. In these animals, the transgenic IL-2R $\beta$ is prematurely expressed on preselection thymocytes (Supplementary Figure 6A) and further overexpressed on postselection mature $\mathrm{T}$ cells (Supplementary Figure 6A). Consequently, the IL-2R $\beta$ is abundantly expressed on both immature and mature thymocytes of IL- $2 \mathrm{R} \beta^{\mathrm{Tg}}$ mice. Among $i \mathrm{NKT}$ cells, immature $\mathrm{HSA}^{\text {hi }} \mathrm{CD}^{-} 4^{-} i \mathrm{NKT}$ cells (ST0) normally do not express IL-2R $\beta$ (Supplementary Figure 6B). However, the ST0 $i$ NKT cells in IL$2 \mathrm{R} \beta^{\mathrm{Tg}}$ mice displayed substantially increased abundance of IL$2 \mathrm{R} \beta$ (Supplementary Figure 6B). Importantly, such premature expression of IL-2R $\beta$ dramatically impaired the generation of $i$ NKT cells, so that the frequency and number of thymic $i$ NKT cells in IL-2R $\beta^{\mathrm{Tg}}$ mice were markedly reduced (Figure 4A). These results suggested that IL-2 receptor signaling in immature $i \mathrm{NKT}$ is detrimental to the generation of thymic $i \mathrm{NKT}$ cells. These findings also indicated that the timing of IL-2R $\beta$ expression during $i \mathrm{NKT}$ cell development needs to be carefully controlled, presumably to protect immature $i \mathrm{NKT}$ cells from premature IL-2 or IL-15 signaling.

\section{Forced Expression of IL-2R $\beta$ Suppresses the Generation of NKT1 Cells in BALB/c Mice}

Because IL-2R $\beta$ is associated with NKT1 cell differentiation, we next aimed to interrogate if premature IL-2R $\beta$ expression in immature ST0 $i$ NKT cells would affect the development of other $i$ NKT subsets. In C57BL/6 mice, most thymic $i$ NKT cells correspond to NKT1 cells (10), making it difficult to discern 


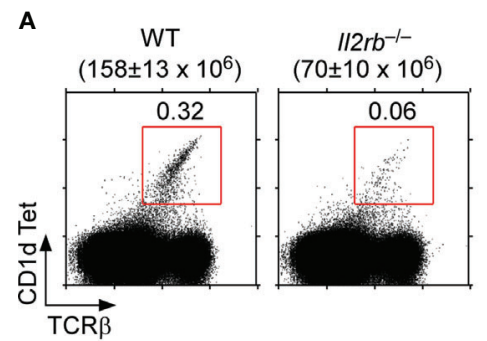

B

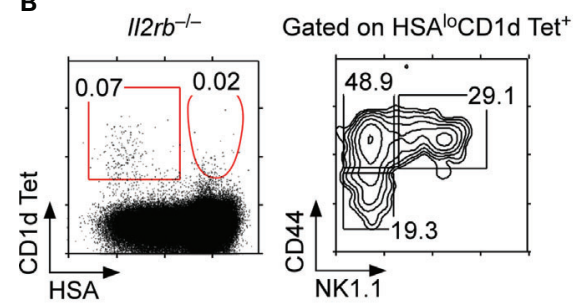

C
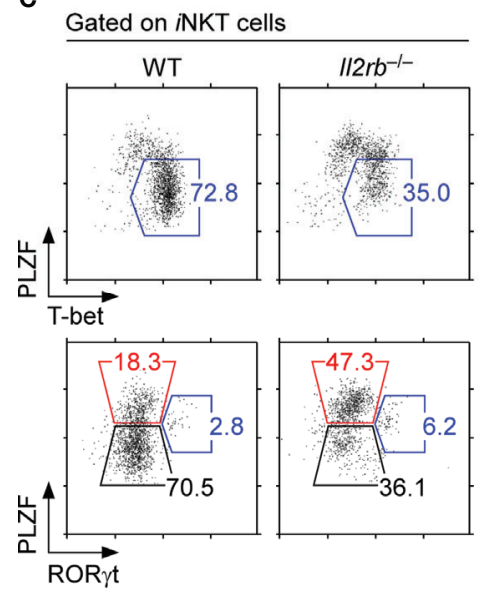

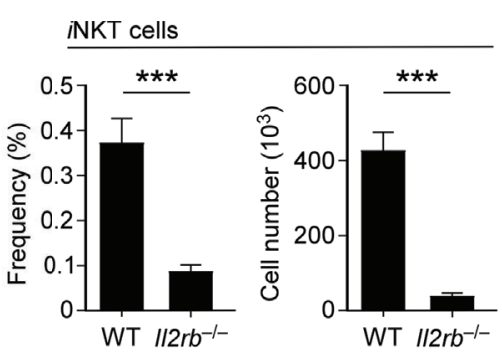

iNKT stages
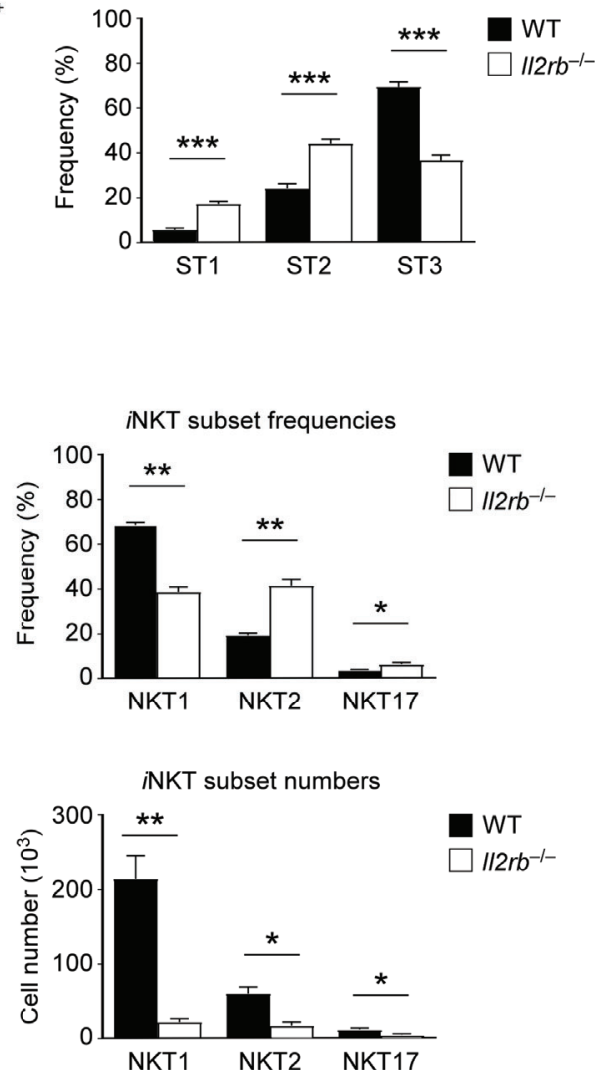

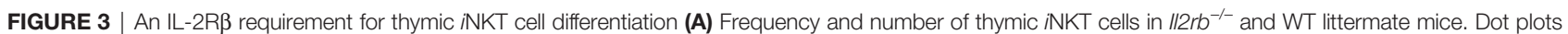
show thymic iNKT cells as identified by CD1dTet and TCR $\beta$ staining. Total thymocyte numbers are shown above the dot plots as the means \pm SEM (left). Bar graphs show the frequencies and numbers of $i N K T$ cells from the indicated mice (right). The dot plot is representative, and the bar graphs are a summary of 4 independent experiments with a total of $13 / 12 r^{-/-}$and 7 WT littermate mice. (B) Thymic iNKT cell differentiation in $/ 12 r b^{-1-}$ mice. HSA ${ }^{l o}$ mature $i N K T$ cells were stained for CD44 and NK1.1 to identify ST1, ST2, and ST3 cells in the indicated mice (left). The bar graph shows the frequencies of ST1, ST2, and ST3 cells in II2rb ${ }^{-/}$and WT littermate mice (right). The dot and contour plots are representative, and the bar graph shows the summary of 4 independent experiments. (C) Dot plots show the thymic iNKT subset composition in $/ 12 \mathrm{rb}^{-/-}$and WT littermate mice (left). The bar graph on top shows the frequency of thymic iNKT subsets as summary of 5 independent experiments with a total of $14 / 12 \mathrm{rb}^{-/-}$and $8 \mathrm{WT}$ littermate mice. The bottom bar graph shows the cell numbers of thymic iNKT subsets as the summary of 4 independent experiments with a total of $9 / 12 \mathrm{rb}^{-/-}$and $4 \mathrm{WT}$ littermate control mice. ${ }^{*} \mathrm{P}<0.05 ;{ }^{* *} \mathrm{P}<0.01 ;{ }^{* \star *} \mathrm{P}<0.001$.

how the IL-2R $\beta^{\mathrm{Tg}}$ would affect NKT2 and NKT17 cells which are underrepresented in this mouse strain. BALB/c mice differ from $\mathrm{C} 57 \mathrm{BL} / 6$ mice in their thymic $i \mathrm{NKT}$ subset composition as it is enriched in NKT2 and NKT17 cells and reduced in NKT1 cells compared with that in C57BL/6 mice (10). Thus, we considered $\mathrm{BALB} / \mathrm{c}$ mice as an appropriate model to assess the effects of premature IL-2R $\beta$ expression on NKT2 and NKT17 cell generation. To this end, we backcrossed the IL- $2 \mathrm{R} \beta^{\mathrm{Tg}}$ onto the
BALB/c background and analyzed the development and differentiation of thymic $i$ NKT cells in these mice.

As expected, the thymocytes of IL- $2 \mathrm{R} \beta^{\mathrm{Tg}} \mathrm{BALB} / \mathrm{c}$ mice expressed substantially increased amounts of surface IL-2R $\beta$ compared with the thymocytes of littermate mice (Supplementary Figure 6C). Such increase in the IL-2R $\beta$ abundance was also observed in $\mathrm{HSA}^{\text {hi }} \mathrm{CD} 44^{-}$(ST0) immature $i$ NKT cells (Supplementary Figure 6D), but curiously not in 

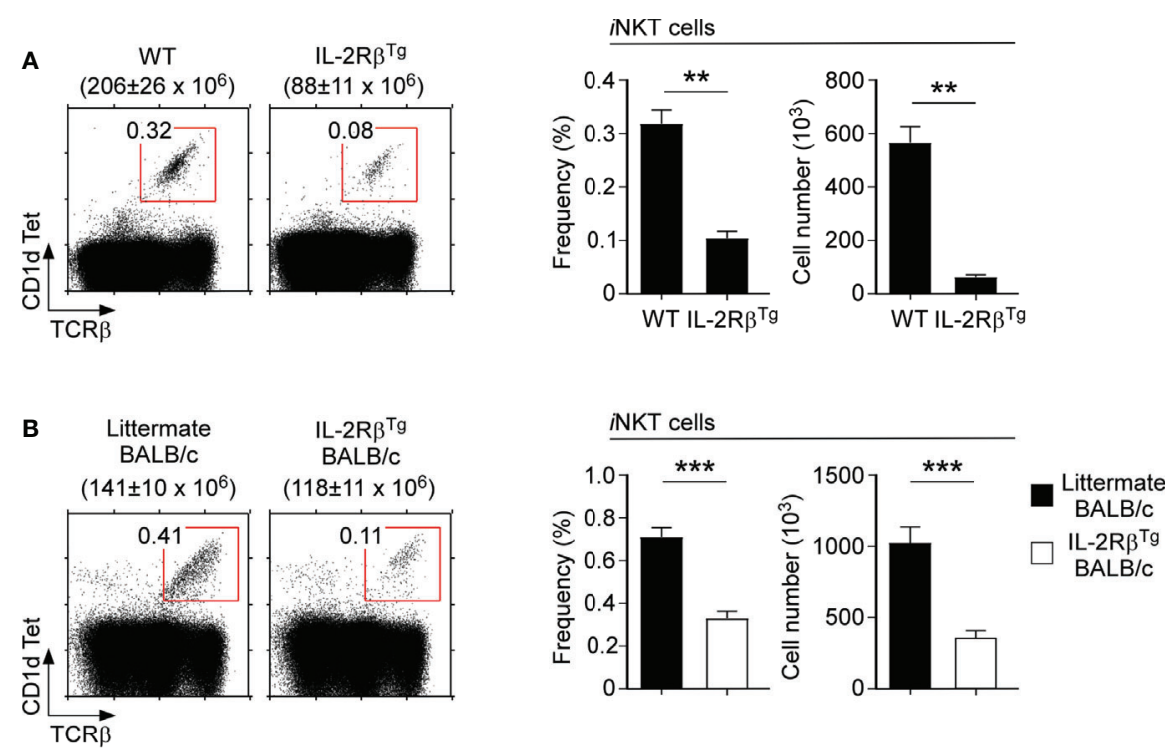

C
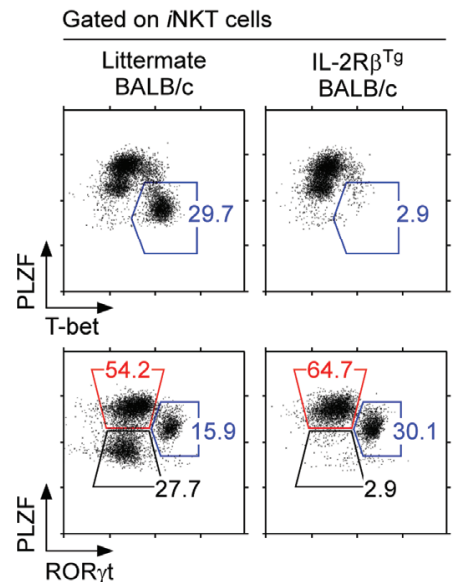
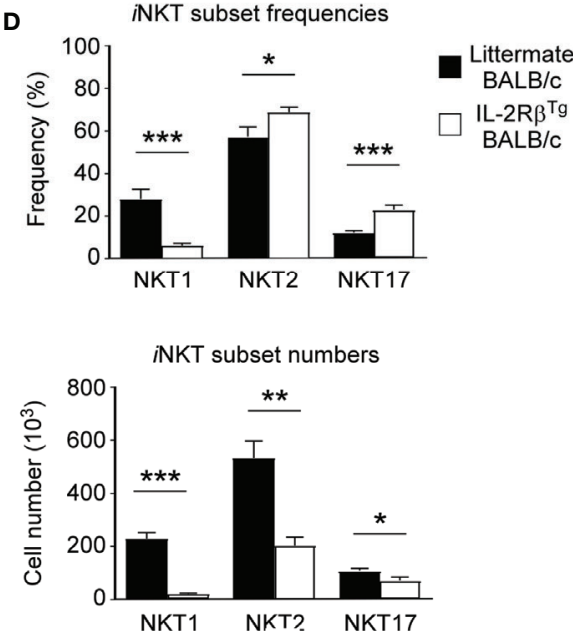

FIGURE 4 | iNKT cell differentiation in IL-2R $\beta$ transgenic mice (A) Frequency and number of thymic INKT cells in IL-2R $\beta^{\text {Tg }}$ and littermate C57BL/6 mice. The dot plots show thymic NKT cells as identified by CD1dTet versus TCR $\beta$ staining (left). The total thymocyte numbers are shown above the dot plots as the means \pm SEM. The bar graphs show the frequencies and numbers of INKT cells from the indicated mice (right). The dot plot is representative, and the bar graphs are a summary of 4 independent experiments with a total of $7 \mathrm{IL}-2 \mathrm{R} \beta^{\mathrm{Tg}}$ and 6 littermate C57BL/6 mice. (B) Frequency and number of thymic $i N K T$ cells in IL-2R $\beta^{T g} \mathrm{BALB} / \mathrm{c}$ and littermate WT mice. The dot plots show thymic INKT cells as identified by CD1dTet versus TCR $\beta$ staining (left). The total thymocyte numbers are shown above the dot plots as the means \pm SEM. The bar graphs show the frequencies and numbers of iNKT cells from the indicated mice (right). The dot plot is representative, and the bar graphs are a summary of 3 independent experiments with a total of $7 \mathrm{IL}-2 \mathrm{R} \beta^{\mathrm{Tg}}$ and 8 littermate WT mice. (C) The dot plots show the thymic NKKT subset composition in IL-2R $\beta^{T g}$ BALB/c and WT littermate mice based on PLZF versus T-bet (top) and PLZF versus RORyt analysis (bottom). Results are representative of 4 independent experiments. (D) The bar graphs show the summary of thymic iNKT subset distribution for the indicated mice. Subset frequencies are the summary of 5 independent experiments with a total of $10 \mathrm{IL}-2 \mathrm{R} \beta^{\mathrm{Tg}}$ and 10 littermate WT BALB/c mice (top). Cell numbers of each iNKT subset are the summary of 4 independent experiments with a total of $8 \mathrm{IL}-2 \mathrm{R} \beta^{\mathrm{Tg}}$ and 7 littermate WT BALB/c control mice (bottom). ${ }^{*} \mathrm{P}<0.05$; ${ }^{\star \star} \mathrm{P}<0.01$; ${ }^{\star \star \star} \mathrm{P}<0.001$.

HSA $^{\text {lo }}$ mature $i$ NKT cells (Supplementary Figure 6D). These results suggested that the expression of the IL-2R $\beta^{\mathrm{Tg}}$ is either silenced in $\mathrm{HSA}^{\mathrm{lo}} i \mathrm{NKT}$ cells or that the premature expression of IL-2R $\beta$ in $\mathrm{HSA}^{\text {hi }} \mathrm{CD} 44^{-}$(ST0) immature $i \mathrm{NKT}$ cells is detrimental for $i$ NKT cell generation so that only $i$ NKT cells that have escaped the transgene expression can mature. In fact, we found that the frequency and number of thymic $i$ NKT cells were indeed dramatically reduced in $\mathrm{IL}-2 \mathrm{R} \beta^{\mathrm{Tg}} \mathrm{BALB} / \mathrm{c}$ mice (Figure 4B). Thus, consistent with our findings in IL-2R $\beta^{\mathrm{Tg}}$ C57BL/6 mice (Figure 4A), the forced expression of IL-2R $\beta$ suppresses the generation of thymic $i \mathrm{NKT}$ cells in BALB/c mice also (Figure 4B).

To understand the effects of IL-2R $\beta$ on $i$ NKT cell differentiation, we next examined the $i$ NKT subset composition 
in IL-2R $\beta^{\mathrm{Tg}} \mathrm{BALB} / \mathrm{c}$ mice. Surprisingly, NKT1 cells, as identified by T-bet expression, were virtually absent in IL-2R $\beta^{\text {Tg }} \mathrm{BALB} / \mathrm{c}$ thymocytes. Both the frequency and number of T-bet ${ }^{+}$NKT1 cells were dramatically decreased in these mice (Figures 4C, D). Conversely, NKT2 and NKT17 cell frequencies were significantly increased in IL-2R $\beta^{\mathrm{Tg}} \mathrm{BALB} / \mathrm{c}$ mice compared with those of WT littermate controls (Figures 4C, D). Thus, transgenic IL-2R $\beta$ selectively inhibited the development of NKT1 cells without suppressing the generation of NKT2 and NKT17 cells.

To further examine how IL-2R $\beta^{\mathrm{Tg}}$ would interfere with the induction of T-bet and impair NKT1 cell generation, we employed the $\mathrm{T}$-bet-ZsGreen reporter mouse $\left(\mathrm{TBGR}^{\mathrm{Tg}}\right.$ ) to monitor T-bet transcription in IL-2R $\beta^{\mathrm{Tg}}$ and $\mathrm{WT}$ BALB/c mice (Figure 5A) (25). The $\mathrm{TBGR}^{\mathrm{Tg}}$ is designed to express ZsGreen reporter proteins from the $T b \times 21$ gene locus which encodes for $\mathrm{T}$ bet so that ZsGreen expression reflects Tbx21 transcription (25). Indeed, we identified a substantial population of $\mathrm{ZsGreen}^{+}$cells among thymic $i \mathrm{NKT}$ cells of $\mathrm{TBGR}^{\mathrm{Tg}} \mathrm{BALB} / \mathrm{c}$ mice (Figure $\mathbf{5 A}$ ), and these $\mathrm{ZsGreen}{ }^{+} i \mathrm{NKT}$ cells corresponded to NKT1 cells based on their intracellular PLZF and T-bet protein expression (Figure $\mathbf{5 B}$, left). In contrast, $\mathrm{TBGR} \mathrm{R}^{\mathrm{Tg}} \mathrm{IL}-2 \mathrm{R} \beta^{\mathrm{Tg}} \mathrm{BALB} / \mathrm{c}$ failed to generate $\mathrm{ZsGreen}^{+} \mathrm{T}$-bet ${ }^{+} i \mathrm{NKT}$ cells (Figure 5B, right), affirming the detrimental effect of IL-2R $\beta^{\mathrm{Tg}}$ on NKT1 cell generation.

Of note, we found in both WT and IL- $2 \mathrm{R} \beta^{\mathrm{Tg}}$ thymocytes a distinct population of $i$ NKT cells with intermediate amounts of ZsGreen and T-bet expression, i.e. ZsGreen ${ }^{\text {int }}{ }^{\mathrm{T}}$-bet ${ }^{\text {int }}$ (Figure $\mathbf{5 B}$, cells gated in blue), whose developmental status was unclear to us. To further characterize these ZsGreen ${ }^{\text {int }}$ T-bet $^{\text {int }} i \mathrm{NKT}$ cells, we divided $\mathrm{TBGR}^{\mathrm{Tg}} \mathrm{BALB} / \mathrm{c} i \mathrm{NKT}$ cells into 3 populations, i.e. I, II, and III, based on their progressive increase in ZsGreen reporter expression. Accordingly, the ZsGreen ${ }^{\text {int }} \mathrm{T}$-bet ${ }^{\text {int }}$ cells corresponded to population II, while ZsGreen ${ }^{\text {hi }} \mathrm{T}$-bet ${ }^{\text {hi }}$ cells were defined as population III (Figure 5C). Thymic $i$ NKT cells that did not express ZsGreen were referred to as population I. Terminally differentiated NKT1 cells, as identified as population III, expressed large amounts of T-bet and CD44 (Figure 5C and Supplementary Figure 6E) (11). ZsGreen ${ }^{\text {int }} \mathrm{T}$ bet $^{\text {int }}$ cells (population II), on the other hand, expressed significantly smaller amounts of T-bet and CD44 but showed greater abundance of TCR $\beta$. Importantly, ZsGreen ${ }^{\text {int }}$ T-bet $^{\text {int }}$ cells had not yet induced CD122 expression, suggesting that they are NKT1-lineage committed but not fully differentiated NKT1 cells (Figures 5C, D and Supplementary Figure 6E) (35). Along these lines, the ZsGreen ${ }^{\text {int }}{ }^{T}$-bet ${ }^{\text {int }}$ population did not contain ROR $\gamma t^{+} i \mathrm{NKT}$ cells (Figure 5D), indicating that NKT17 cell differentiation is branched off before the appearance of ZsGreen ${ }^{\text {int }}$ T-bet $^{\text {int }}$ population II $i$ NKT cells. Thus, we identified a new subpopulation of thymic $i$ NKT cells, i.e. ZsGreen ${ }^{\text {int }}$ T-bet $^{\text {int }}$ $i$ NKT cells, that are NKT1-lineage committed but are not fully differentiated into mature NKT1 cells. Because ZsGreen ${ }^{+} \mathrm{T}$-bet ${ }^{+}$ $i \mathrm{NKT}$ cells were missing in IL- $2 \mathrm{R} \beta^{\mathrm{Tg}}$ thymocytes, these results further suggest that the forced and premature expression of IL$2 \mathrm{R} \beta$ interferes with the terminal differentiation of T-bet ${ }^{+} \mathrm{NKT} 1$ cells but did not inhibit the induction of T-bet expression itself. Collectively, these results unveil an unexpected negative effect of IL-2R $\beta$ on $i$ NKT subset differentiation.

\section{Thymic iNKT Cell Differentiation in IL-15- Infused IL-2R $\beta^{\text {Tg }}$ BALB/c Mice}

To understand how IL-2R $\beta$ overexpression would affect thymic $i$ NKT cell generation, we considered two alternative but not mutually exclusive hypotheses. First, the increased abundance of IL-2R $\beta$ proteins in IL- $2 \mathrm{R} \beta^{\mathrm{Tg}}$ mice could increase the binding and consumption of IL-15, thus diminishing the availability of IL-15 for $i$ NKT cell development. IL-15 is critical for the generation of $i$ NKT cells in general and specifically for NKT1 cells $(11,36)$. Consequently, the detrimental effect of IL-2R $\beta^{\text {Tg }}$ on $i$ NKT cells could have been due to insufficient IL-15 availability, partly phenocopying the effect of IL-15-deficiency (37). In a second scenario, we focused on the timing of IL-2R $\beta$ expression. IL-2R $\beta$ is normally not induced in immature $i \mathrm{NKT}$ cells but forcibly expressed in IL- $2 \mathrm{R} \beta^{\mathrm{Tg}}$ mice. Premature IL-2R $\beta$ signaling could interfere with $i$ NKT cell generation and specifically with NKT1 cell differentiation, albeit the molecular mechanism would be unclear. To discriminate between these possibilities, we implanted IL- $2 \mathrm{R} \beta^{\mathrm{Tg}}$ mice with osmotic pumps that release recombinant IL-15 to supply excess amounts of IL-15 in vivo (Figure 6A). After 10 days of IL-15 pump installation in IL- $2 \mathrm{R} \beta^{\mathrm{Tg}}$ mice, we found a dramatic increase in spleen size and increased frequencies of NK cells whose maintenance depends on IL-15 (38) (Figure 6A and Supplementary Figure 7A). Moreover, the frequency of CD8 T cells and specifically the number of $\mathrm{CD} 44^{\text {hi }} \mathrm{CXCR}^{+}$memoryphenotype CD8 T cells were substantially increased in mice that were implanted with IL-15- but not with PBS-releasing pumps (Figure 6A and Supplementary Figure 7B). These results were consistent with the effects of increased IL-15 availability in vivo (39). The generation of thymic $i \mathrm{NKT}$ cells in IL-2R $\beta^{\mathrm{Tg}} \mathrm{BALB} / \mathrm{c}$ mice, however, remained unaffected by the IL-15 infusion (Figure 6B), and the $i$ NKT subset composition also remained unaltered (Figures 6C, D). Thus, despite supplemented with excess amounts of IL-15, the IL-2R $\beta^{\mathrm{Tg}}$ mice were still impaired in thymic $i \mathrm{NKT}$ cell differentiation, with both dramatically reduced frequencies and numbers of NKT1 cells (Figures 6C, D). Along these lines, the thymic generation of Foxp $3^{+}$Treg cells which depend on IL-2 and IL-2 receptor signaling (33) was unaffected in IL-2R $\beta^{\mathrm{Tg}}$ mice (Supplementary Figure 7C), which further supports that the availability of intrathymic cytokines remains unaltered by IL-2R $\beta$ overexpression. Altogether, these results suggested that it is unlikely that increased consumption and reduced availability of in vivo IL-15 would account for the lack of NKT1 cells in IL$2 \mathrm{R} \beta^{\mathrm{Tg}}$ mice.

\section{Constitutively Active STAT5 Suppresses the Development of Thymic iNKT Cells}

To gain further mechanistic insights into whether and how premature IL-2R $\beta$ expression would impair $i$ NKT cell generation, we considered that STAT5 phosphorylation is a major downstream event of IL-2R $\beta$ signaling (40). The transcription factor STAT5 plays a critical role in $\mathrm{T}$ cell development as it induces the expression of prosurvival molecules, such as Bcl-2, and controls the activity of several key transcription factors in T cell differentiation $(40,41)$. Because immature ST0 $i$ NKT cells lack IL-2R $\beta$ (Figure 1C), we postulated that ST0 $i$ NKT cells of WT mice would not induce 

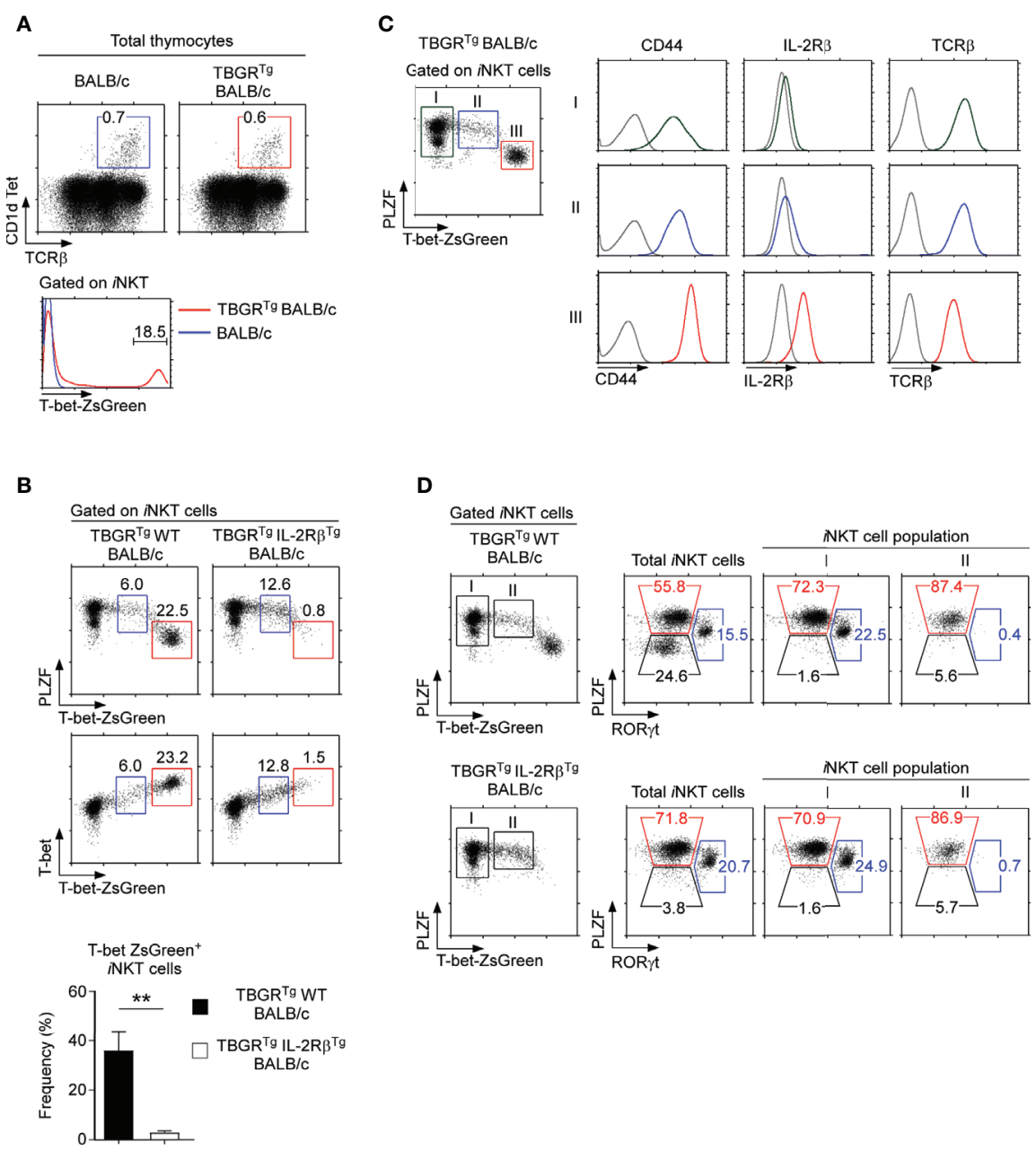

FIGURE 5 | T-bet-ZsGreen reporter expression in iNKT cells of IL-2R $\beta^{\text {Tg }}$ BALB/c mice (A) Thymic iNKT cells were identified in BALB/c and TBGR ${ }^{T g}$ BALB/c mice (top) and assessed for T-bet-ZsGreen reporter expression (bottom). Results are representative of 5 independent experiments. (B) T-bet-ZsGreen reporter expression in thymic iNKT cells of TBGR ${ }^{T / L} / L-2 R \beta^{T g}$ BALB/c and TBGR ${ }^{T g}$ littermate control mice. Dot plots show either PLZF versus T-bet-ZsGreen reporter expression (top) or

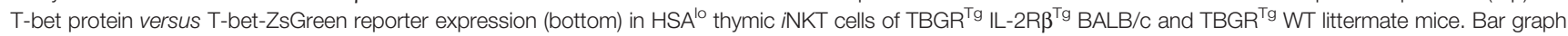
shows the frequency of T-bet-ZsGreen ${ }^{+}$iNKT cells (red box) of the indicated mice. Results are representative 3 independent experiments with 8 TBGR ${ }^{T g} / L-2 R \beta^{T g}$ BALB/c and 5 TBGR $^{T g}$ littermate WT BALB/c mice. (C) T-bet-ZsGreen reporter expression upon NKT1 cell differentiation. Thymic iNKT cells of TBGR ${ }^{\text {Tg }}$ BALB/c mice were divided into three distinct populations, i.e. I, II, and III, based on the amount of T-bet-ZsGreen expression (dot plot, left). Surface expression of CD44, IL-2R $\beta$,

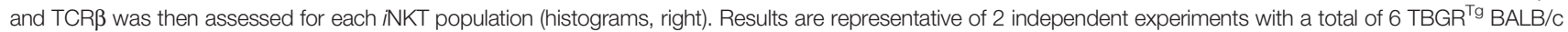
mice. (D) Subset compositions of thymic iNKT cells in TBGR ${ }^{T g}$ BALB/c mice based on ZsGreen-reporter expression. Total iNKT cells, T-bet-ZsGreen-negative (population I), and T-bet-ZsGreen-intermediate (population II) iNKT cells were identified in TBGR ${ }^{T g}$ WT BALB/c (top) and TBGR ${ }^{T g} / L-2 R \beta^{T g}$ BALB/c thymocytes (bottom) and examined for their subset composition based on PLZF versus ROR $\gamma$ t staining. Results are representative of 3 independent experiments with 8 TBGR $^{\text {Tg IL-2R }}{ }^{\text {Tg }}$ BALB/c and 5 TBGR ${ }^{\text {Tg }}$ littermate WT BALB/c mice. ${ }^{\star *} \mathrm{P}<0.01$.

phospho-STAT5 (pSTAT5) upon IL-15 stimulation. ST0 $i$ NKT cells in IL-2R $\beta^{\mathrm{Tg}}$ mice, on the other hand, would have induced substantial amounts of PSTAT5 due the premature expression and signaling of IL-2R $\beta$.

If it would be the premature STAT5 activation which suppresses $i \mathrm{NKT}$ cell generation, we hypothesized that a constitutively active STAT5b transgene (CA-STAT5 ${ }^{\mathrm{Tg}}$ ) would also impair $i$ NKT cell generation (24). Indeed, we found that both the frequency and number of thymic $i \mathrm{NKT}$ cells were dramatically reduced in CA-STAT5 ${ }^{\mathrm{Tg}}$ mice compared to those in WT littermate controls (Figure 6E). Moreover, assessing the composition of thymic $i$ NKT subsets in CA-STAT5 ${ }^{\text {Tg }}$ mice (Supplementary Figure 8A) demonstrated that the generation of NKT1 cells was impaired by ectopic STAT5 activation (Figure 6F). T cell development in general, however, was not negatively affected by the constitutive activation of STAT5 (Supplementary Figure 8B). As such, the cell numbers of preselection DP thymocytes remained unaffected (Figure $6 \mathbf{F}$ ), and the generation of memory-phenotype CD8 $\mathrm{T}$ cells was rather increased in CA-STAT5 ${ }^{\mathrm{Tg}}$ thymocytes (Supplementary Figure 8C). Thus, the detrimental effect of STAT5 activation was limited to the generation of $i$ NKT cells. Collectively, these results identify 
A

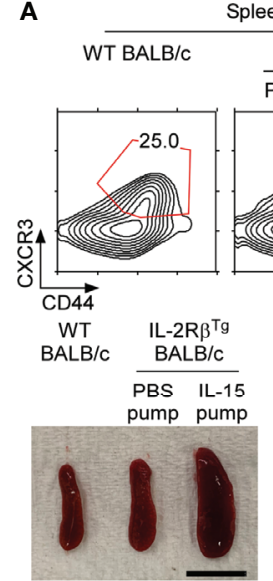

Spleen CD8 T cells

IL-2R $\beta^{\mathrm{Tg}} \mathrm{BALB} / \mathrm{c}$

PBS-pump

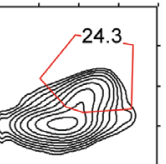

Spleen CD8 T cels

$\mathrm{CD}^{\mathrm{h}} 4^{\mathrm{hi}} \mathrm{CXCR} 3^{+}$

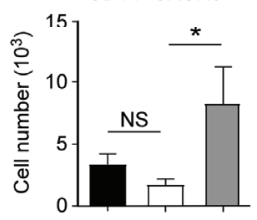

D

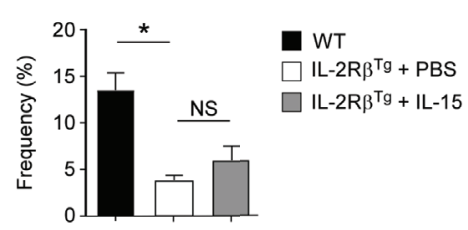

NKT1 cell numbers

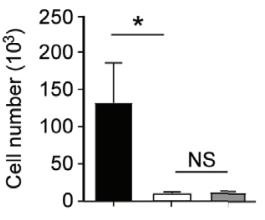

B

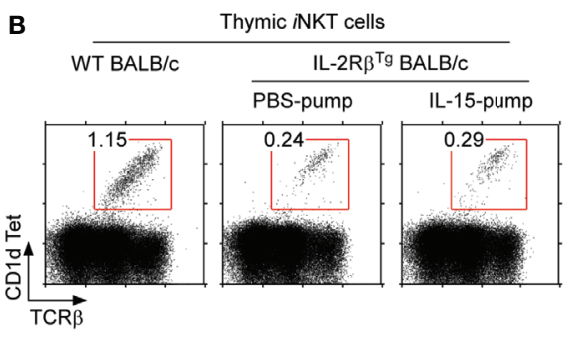

iNKT cells
E

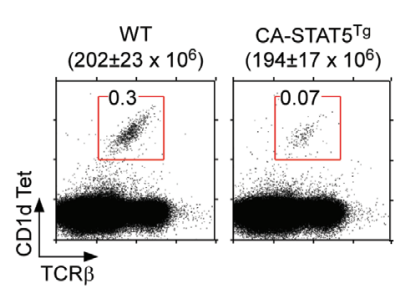

F

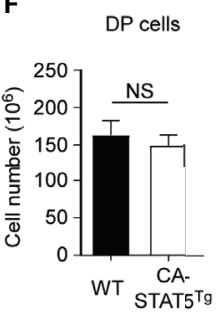

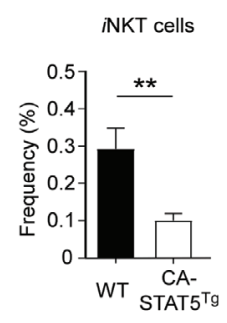

NKT1 cells

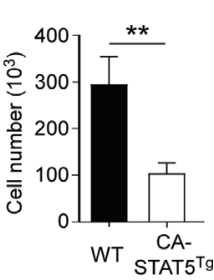

C

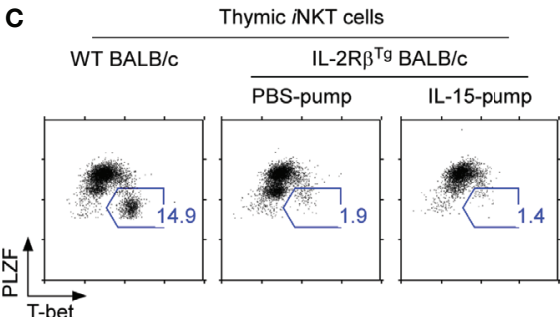

WT
$\square$ IL-2R $\beta^{T g}+$ PBS

$\square$ IL-2R $\beta^{T g}+$ IL-15

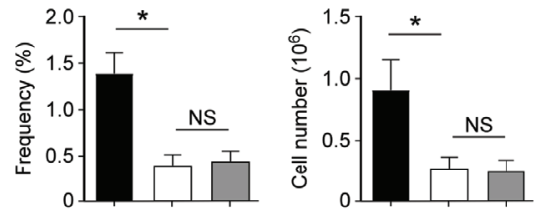

Thymic NKT cells 
and demonstrate STAT5 as a major player acting downstream of IL-2R $\beta$ to control the development of thymic $i$ NKT cells.

\section{DISCUSSION}

$i$ NKT cells comprise three major subsets that are characterized by distinct transcription factor and cytokine expression. Although TCR signaling is considered to play a decisive role in the generation and subset differentiation of $i$ NKT cells $(42,43)$, intrathymic cytokines also play important roles in these processes (44). As such, the $\gamma_{c}$ family cytokine IL-15 is a critical factor in thymic iNKT cell generation that also contributes to the subset specification of iNKT cells (11). Consistent with an IL-15 requirement for NKT1 cell differentiation, the signaling-competent IL-15 receptor heterodimer-i.e., IL-2R $\beta / \gamma c$-is mostly expressed on NKT1 cells, but not on NKT2 and NKT17 cells (10). This raises the question whether IL-2R $\beta$ expression is specifically induced on NKT1 cells or whether IL-2R $\beta$ could be induced on all $i$ NKT cells but is then terminated upon differentiation into NKT2 and NKT17 cells. Furthermore, it was unclear whether IL-2R $\beta$ expression would be sufficient to impose NKT1 subset fate so that forced expression of IL-2R $\beta$ would direct $i$ NKT cells into NKT1 cells. Here, we addressed these questions using a series of genetically engineered mouse models, and we identified IL-2R $\beta$ as a critical regulator of thymic $i$ NKT cell generation whose abundance and timing of expression dramatically affected the generation of $i \mathrm{NKT}$ cells. These findings reveal previously unappreciated aspects of cytokine receptor expression in controlling the development of $i \mathrm{NKT}$ cells, and they propose a model of $i$ NKT differentiation that is regulated by the timing and abundance of cytokine receptor expression.

The generation of thymic $i$ NKT cells is currently explained by two competing but not mutually exclusive models of differentiation $(7,45)$. In the conventional or "linear maturation" model, preselection thymocytes that have recombined a functional Vo14-Jo18 TCR $\alpha$ chain are positively selected to become immature ST0 $i$ NKT cells. ST0 $i$ NKT cells then mature along a developmental pathway defined by CD44 and NK1.1 expression, culminating in end differentiated CD $44^{+} \mathrm{NK} 1.1^{+} \mathrm{ST} 3$ iNKT effector cells. Under this scenario, CD $44^{+} \mathrm{NK} 1.1^{-} \mathrm{ST} 2$ iNKT cells, which are IL-2R $\beta$-negative, would give rise to ST3 $i$ NKT cells that are IL-2R $\beta$ positive. However, the cellular signals that would induce the initial upregulation of IL-2R $\beta$ remain unknown. Notably, such a requirement for IL-2R $\beta$ expression that precedes the IL-15mediated generation of NKT1 cells is also found in the alternative "lineage differentiation" model $(7,45)$. While NKT1 cell differentiation depends on IL-15, the IL-2R $\beta$, which is necessary for IL-15 signaling, is not expressed on immature $i$ NKT cells. Thus, IL-2R $\beta$ expression is carefully timed so that preselection thymocytes lack IL-2R $\beta$ but is then specifically induced on NKT1-committed postselection immature $i$ NKT cells to drive their maturation into NKT1 subset $i \mathrm{NKT}$ cells.

The molecular pathway that upregulates IL-2R $\beta$ and drives NKT1 cell fate is not fully understood. However, it likely involves molecules downstream of TCR signaling because differences in TCR signaling strength are acknowledged to drive $i$ NKT subset fate decisions (42). In this regard, the transcription factor Egr2 is of particular interest (46), because its relative abundance is associated with $i \mathrm{NKT}$ subset differentiation (42). Egr2 expression is upregulated by TCR-induced calcium signaling and correlates with the strength of TCR signaling $(42,47)$. Notably, NKT2 cell generation is thought to be driven by strong TCR signaling whereas NKT1 cell differentiation is proposed to be mediated by weak TCR signaling (42). Incidentally, NKT2 cells contain large amounts of Egr2 whereas NKT1 cells express small amounts of Egr2. Such distinct amounts of Egr2 expression presumably results in the graded expression of PLZF whose abundance correlates with $i$ NKT subset specification (48). Thus, the TCR-centric view proposes that distinct amounts of Egr2 would induce different levels of PLZF, which would then determine iNKT subset identity. Interestingly, however, Egr2 was also found to bind the IL-2R $\beta$ promoter and thus to induce IL-2R $\beta$ expression (47). Consequently, we hypothesized that Egr2 could induce the expression of IL-2R $\beta$ in immature $i \mathrm{NKT}$ cells to permit their differentiation into NKT1 cells. According to this scenario, TCR signaling would be required to specify NKT1 fate by upregulating IL-2R $\beta$ expression, and cytokine receptor signaling would be then required to drive NKT1 subset differentiation by IL-15 signaling. Altogether, such model reconciles the two concurrent perspectives of $i$ NKT cell development so that TCR and cytokine signals play distinct but nonredundant roles in the subset differentiation of $i$ NKT cells.

Because IL-2R $\beta$ plays such a critical role in NKT1 subset commitment, we were surprised to find that the increased abundance of IL-2R $\beta$ in IL- $2 \mathrm{R} \beta^{\mathrm{Tg}}$ mice did not promote but rather suppressed the generation of thymic $i \mathrm{NKT}$ cells, specifically of the NKT1 subset. A detrimental effect of forced IL-2R $\beta$ expression had been previously reported for NK cells where a hematopoietic lineage-specific IL-2R $\beta$ transgene was found to suppress the generation of NK1.1 $1^{+}$cells (49). Whether this NK1. $1^{+}$population also comprise $i \mathrm{NKT}$ cells, including stage 3 NKT1 cells, is unclear from that study. If such would be the case, however, these results would further bolster a detrimental effect of IL-2R $\beta$ on $i$ NKT cell generation whose molecular basis remains currently unclear to us.

Nonetheless, we considered two important findings regarding the generation of $i \mathrm{NKT}$ cells in IL-2R $\beta^{\mathrm{Tg}}$ mice. First, unlike NKT1 cells, NKT2 and NKT17 cells in WT mice do not express IL-2R $\beta$ (10) Surprisingly, we found that the few NKT2 and NKT17 cells that arise in IL-2R $\beta^{\mathrm{Tg}}$ mice also did not express IL$2 \mathrm{R} \beta$ proteins. Therefore, the NKT2 and NKT17 cells in IL-2R $\beta^{\mathrm{Tg}}$ mice could be either transgene escapees or they could have downregulated the expression of transgenic IL-2R $\beta$. We favor the latter case because the IL- $2 \mathrm{R} \beta^{\mathrm{Tg}}$ is driven by the human $C D 2$ mini-cassette, whose activity is downregulated upon positive selection, so that transgene expression substantially diminishes in postselection thymocytes (50). Regardless, we consider the IL$2 \mathrm{R} \beta^{\mathrm{Tg}}$ model not adequate to assess the effect of forced IL-2R $\beta$ expression on NKT2 and NKT17 cells, simply because the IL- 
$2 \mathrm{R} \beta^{\mathrm{Tg}}$ fails to be expressed in these $i \mathrm{NKT}$ subsets. Second, we wish to underscore that the IL- $2 \mathrm{R} \beta^{\mathrm{Tg}}$ is prematurely expressed on immature thymocytes, including the immature ST0 $i \mathrm{NKT}$ cells. IL-2R $\beta$ is normally absent in the ST0 $i$ NKT precursors of WT mice, an observation contrasting the IL-2R $\beta$ expression in IL-2R $\beta^{\mathrm{Tg}}$ ST0 $i$ NKT cells which are highly abundant in IL-2R $\beta$. Consequently, ST0 $i \mathrm{NKT}$ cells in IL-2R $\beta^{\mathrm{Tg}}$ mice can be signaled by intrathymic IL-15 whereas WT ST0 iNKT cells cannot respond to IL-15. Based on these results, we hypothesize that premature and possibly sustained IL-15 signaling in immature ST0 $i$ NKT cells would be detrimental for NKT1 cell generation.

Additionally, we appreciate the need to determine why premature IL-15 signaling in ST0 $i$ NKT cells would negatively affect thymic $i$ NKT cell generation. IL-15-induced STAT5 phosphorylation is usually considered beneficial for $\mathrm{T}$ cells because it induces the expression of anti-apoptotic Bcl-2 and upregulates metabolic activities. Thus, IL-15 signaling should promote and not inhibit $i$ NKT cell generation. However, STAT5 activation also suppresses the induction of Bcl6, which is a critical transcription factor for $i$ NKT cell generation (51). Bcl-6 is selectively and highly expressed on ST0 $i$ NKT cells before they proliferate and differentiate into mature $i$ NKT cells. Bcl-6 is also developmentally necessary because Bcl-6deficiency is associated with impaired thymic $i$ NKT cell generation (51). Importantly, IL-2 receptor-induced pSTAT5 potently suppresses Bcl-6 expression (52-54). Therefore, STAT5 activation in ST0 $i$ NKT cells could suppress the expression of Bcl-6, which, in turn, could impair the generation of thymic $i \mathrm{NKT}$ cells. These results lead to a model of $i$ NKT cell development where IL-2R $\beta$ expression must be precisely timed so that ST0 $i$ NKT cells suppress IL-2R $\beta$ expression to prevent premature IL-15 signaling, but then a subset of post-ST0 $i$ NKT cells would rapidly induce IL-2R $\beta$ to initiate IL-15induced NKT1 lineage differentiation.

Lastly, we wish to point out that the T-bet-ZsGreen reporter mouse revealed a new developmentally intermediate stage in NKT1 cell development that can be identified by intermediate level of T-bet protein expression and T-bet mRNA transcription (as demonstrated by T-bet-ZsGreen reporter expression). Such ZsGreen ${ }^{\text {int }}$ T-bet ${ }^{\text {int }}$ $i$ NKT cells were NKT1 lineage committed but not fully differentiated NKT1 cells, as they lacked ROR $\gamma$ t expression but had not fully upregulated T-bet protein expression. The ZsGreen ${ }^{\text {int }} \mathrm{T}$ bet $^{\text {int }} i$ NKT cells were further marked by their intermediate level of PLZF protein expression which was not downregulated to the amounts found in mature NKT1 cells (48). Thus, ZsGreen ${ }^{\text {int }} \mathrm{T}$ bet $^{\text {int }} i$ NKT cells are NKT1 lineage committed but not fully mature NKT1 cells. Because ZsGreen ${ }^{\text {int }}$ T-bet $^{\text {int }} i$ NKT cells were present in both WT and IL- $2 \mathrm{R} \beta^{\mathrm{Tg}}$ mice, these data indicate that the forced IL2R $\beta$ expression did not interfere with NKT1 lineage commitment but rather with the maturation of NKT1 cells.

\section{REFERENCES}

1. Etzensperger R, Kadakia T, Tai X, Alag A, Guinter TI, Egawa T, et al. Identification of Lineage-Specifying Cytokines That Signal All CD8 (+)-Cytotoxic-Lineage-Fate 'Decisions' in the Thymus. Nat Immunol (2017) 18:1218-27. doi: 10.1038/ni.3847

2. Park JH, Adoro S, Guinter T, Erman B, Alag AS, Catalfamo M, et al. Signaling by Intrathymic Cytokines, Not T Cell Antigen Receptors, Specifies CD8
Collectively, here, we demonstrated the importance of cytokine signaling in NKT1 lineage differentiation by altering the timing and abundance of IL-2R $\beta$ expression, independently of TCR expression or signaling. These results document the significance of cytokines and their receptor expression in determining $i \mathrm{NKT}$ lineage fate, and further suggest a role for cytokines in parallel or in association with TCR signaling to shape the effector function of $\mathrm{T}$ cells.

\section{DATA AVAILABILITY STATEMENT}

The original contributions presented in the study are included in the article/Supplementary Material. Further inquiries can be directed to the corresponding author.

\section{ETHICS STATEMENT}

The animal study was reviewed and approved by National Cancer Institute Animal Care and Use Committee.

\section{AUTHOR CONTRIBUTIONS}

HW designed and performed the experiments, analyzed the data, and contributed to the writing of the manuscript. HK, AC, PA, and RG provided expertise, analyzed the data, and commented on the manuscript. J-HP conceived the project, analyzed the data, and wrote the manuscript. All authors contributed to the article and approved the submitted version.

\section{ACKNOWLEDGMENTS}

We thank Drs. Joo-Young Park (Seoul National University) and Damian Kovalovsky (National Cancer Institute, NIH) for critical review and discussion of this manuscript. This study has been supported by the Intramural Research Program of the US National Institutes of Health, National Cancer Institute, Center for Cancer Research.

\section{SUPPLEMENTARY MATERIAL}

The Supplementary Material for this article can be found online at: https://www.frontiersin.org/articles/10.3389/fimmu.2021. 642856/full\#supplementary-material

Lineage Choice and Promotes the Differentiation of Cytotoxic-Lineage T Cells. Nat Immunol (2010) 11:257-64. doi: 10.1038/ni.1840

3. Lin JX, Leonard WJ. The Common Cytokine Receptor Gamma Chain Family of Cytokines. Cold Spring Harb Perspect Biol (2018) 10:a028449. doi: 10.1101/ cshperspect.a028449

4. Hong C, Luckey MA, Park JH. Intrathymic IL-7: The Where, When, and Why of IL-7 Signaling During T Cell Development. Semin Immunol (2012) 24:1518. doi: 10.1016/j.smim.2012.02.002 
5. Weinreich MA, Odumade OA, Jameson SC, Hogquist KA. T Cells Expressing the Transcription Factor PLZF Regulate the Development of Memory-Like CD8+ T Cells. Nat Immunol (2010) 11:709-16. doi: 10.1038/ni.1898

6. Hemmers S, Schizas M, Azizi E, Dikiy S, Zhong Y, Feng Y, et al. IL-2 Production by Self-Reactive CD4 Thymocytes Scales Regulatory T Cell Generation in the Thymus. J Exp Med (2019) 216:2466-78. doi: 10.1084/ jem.20190993

7. Hogquist K, Georgiev H. Recent Advances in iNKT Cell Development. F1000Res (2020) 9. doi: 10.12688/f1000research.21378.1

8. Gapin L. Development of Invariant Natural Killer T Cells. Curr Opin Immunol (2016) 39:68-74. doi: 10.1016/j.coi.2016.01.001

9. Krovi SH, Gapin L. Invariant Natural Killer T Cell Subsets-More Than Just Developmental Intermediates. Front Immunol (2018) 9:1393. doi: 10.3389/ fimmu.2018.01393

10. Lee YJ, Holzapfel KL, Zhu J, Jameson SC, Hogquist KA. Steady-State Production of IL-4 Modulates Immunity in Mouse Strains and is Determined by Lineage Diversity of Inkt Cells. Nat Immunol (2013) 14:1146-54. doi: 10.1038/ni.2731

11. Gordy LE, Bezbradica JS, Flyak AI, Spencer CT, Dunkle A, Sun J, et al. IL-15 Regulates Homeostasis and Terminal Maturation of NKT Cells. J Immunol (2011) 187:6335-45. doi: 10.4049/jimmunol.1003965

12. Monteiro M, Almeida CF, Agua-Doce A, Graca L. Induced IL-17-Producing Invariant NKT Cells Require Activation in Presence of TGF-Beta and IL1beta. J Immunol (2013) 190:805-11. doi: 10.4049/jimmunol.1201010

13. Lucas B, White AJ, Cosway EJ, Parnell SM, James KD, Jones ND, et al. Diversity in Medullary Thymic Epithelial Cells Controls the Activity and Availability of iNKT Cells. Nat Commun (2020) 11:2198. doi: 10.1038/s41467020-16041-x

14. Catlett IM, Hedrick SM. Suppressor of Cytokine Signaling 1 is Required for the Differentiation of CD4+ T Cells. Nat Immunol (2005) 6:715-21. doi: $10.1038 /$ ni1211

15. Vidalain PO, Laine D, Zaffran Y, Azocar O, Servet-Delprat C, Wild TF, et al. Interferons Mediate Terminal Differentiation of Human Cortical Thymic Epithelial Cells. J Virol (2002) 76:6415-24. doi: 10.1128/jvi.76.13.6415-6424.2002

16. Park JY, Ligons DL, Park JH. Out-Sourcing for Trans-Presentation: Assessing T Cell Intrinsic and Extrinsic IL-15 Expression With Il15 Gene Reporter Mice. Immune Netw (2018) 18:e13. doi: 10.4110/in.2018.18.e13

17. White AJ, Jenkinson WE, Cowan JE, Parnell SM, Bacon A, Jones ND, et al. An Essential Role for Medullary Thymic Epithelial Cells During the Intrathymic Development of Invariant NKT Cells. J Immunol (2014) 192:2659-66. doi: 10.4049/jimmunol.1303057

18. Ohteki T, Ho S, Suzuki H, Mak TW, Ohashi PS. Role for IL-15/IL-15 Receptor Beta-Chain in Natural Killer 1.1+ T Cell Receptor-Alpha Beta+ Cell Development. J Immunol (1997) 159:5931-5.

19. Minagawa $M$, Watanabe $\mathrm{H}$, Miyaji $\mathrm{C}$, Tomiyama $\mathrm{K}$, Shimura $\mathrm{H}$, Ito A, et al. Enforced Expression of Bcl-2 Restores the Number of NK Cells, But Does Not Rescue the Impaired Development of NKT Cells or Intraepithelial Lymphocytes, in IL-2/IL-15 Receptor Beta-Chain-Deficient Mice. J Immunol (2002) 169:4153-60. doi: 10.4049/jimmunol.169.8.4153

20. Waickman AT, Ligons DL, Hwang S, Park JY, Lazarevic V, Sato N, et al. CD4 Effector T Cell Differentiation is Controlled by IL-15 That is Expressed and Presented in Trans. Cytokine (2017) 99:266-74. doi: 10.1016/j.cyto.2017.08.004

21. Chinen T, Kannan AK, Levine AG, Fan X, Klein U, Zheng Y, et al. An Essential Role for the IL-2 Receptor in Treg Cell Function. Nat Immunol (2016) 17:1322-33. doi: 10.1038/ni.3540

22. Suzuki H, Kundig TM, Furlonger C, Wakeham A, Timms E, Matsuyama T, et al. Deregulated T Cell Activation and Autoimmunity in Mice Lacking Interleukin-2 Receptor Beta. Science (1995) 268:1472-6. doi: 10.1126/ science. 7770771

23. Zhang S, Laouar A, Denzin LK, Sant'Angelo DB. Zbtb16 (PLZF) is Stably Suppressed and Not Inducible in Non-Innate T Cells Via T Cell ReceptorMediated Signaling. Sci Rep (2015) 5:12113. doi: 10.1038/srep12113

24. Burchill MA, Goetz CA, Prlic M, O’Neil JJ, Harmon IR, Bensinger SJ, et al. Distinct Effects of STAT5 Activation on CD4+ and CD8+ T Cell Homeostasis: Development of CD4+CD25+ Regulatory T Cells Versus CD8+ Memory T Cells. J Immunol (2003) 171:5853-64. doi: 10.4049/jimmunol.171.11.5853

25. Zhu J, Jankovic D, Oler AJ, Wei G, Sharma S, Hu G, et al. The Transcription Factor T-Bet is Induced by Multiple Pathways and Prevents an Endogenous
Th2 Cell Program During Th1 Cell Responses. Immunity (2012) 37:660-73. doi: 10.1016/j.immuni.2012.09.007

26. Park JY, Kwon J, Kim EY, Fink J, Kim HK, Park JH. CD24(+) Cell Depletion Permits Effective Enrichment of Thymic iNKT Cells While Preserving Their Subset Composition. Immune Netw (2019) 19:e14. doi: 10.4110/in.2019.19.e14

27. Kadakia T, Tai X, Kruhlak M, Wisniewski J, Hwang IY, Roy S, et al. E-ProteinRegulated Expression of CXCR4 Adheres Preselection Thymocytes to the Thymic Cortex. J Exp Med (2019) 216:1749-61. doi: 10.1084/jem.20182285

28. Benlagha K, Kyin T, Beavis A, Teyton L, Bendelac A. A Thymic Precursor to the NK T Cell Lineage. Science (2002) 296:553-5. doi: 10.1126/science.1069017

29. Raberger J, Schebesta A, Sakaguchi S, Boucheron N, Blomberg KE, Berglof A, et al. The Transcriptional Regulator PLZF Induces the Development of CD44 High Memory Phenotype T Cells. Proc Natl Acad Sci USA (2008) 105:1791924. doi: 10.1073/pnas.0805733105

30. Kovalovsky D, Alonzo ES, Uche OU, Eidson M, Nichols KE, Sant'Angelo DB. PLZF Induces the Spontaneous Acquisition of Memory/Effector Functions in T Cells Independently of NKT Cell-Related Signals. J Immunol (2010) 184:6746-55. doi: 10.4049/jimmunol.1000776

31. Lord JD, McIntosh BC, Greenberg PD, Nelson BH. The IL-2 Receptor Promotes Lymphocyte Proliferation and Induction of the C-Myc, Bcl-2, and Bcl-X Genes Through the Trans-Activation Domain of Stat5. J Immunol (2000) 164:2533-41. doi: 10.4049/jimmunol.164.5.2533

32. Cheng G, Yu A, Dee MJ, Malek TR. IL-2R Signaling is Essential for Functional Maturation of Regulatory T Cells During Thymic Development. J Immunol (2013) 190:1567-75. doi: 10.4049/jimmunol.1201218

33. Soper DM, Kasprowicz DJ, Ziegler SF. IL-2Rbeta Links IL-2R Signaling With Foxp3 Expression. Eur J Immunol (2007) 37:1817-26. doi: 10.1002/ eji.200737101

34. Keller HR, Kim HK, Jo Y, Gress RE, Hong C, Park JH. The Abundance and Availability of Cytokine Receptor IL-2Rbeta (CD122) Constrain the Lymphopenia-Induced Homeostatic Proliferation of Naive CD4 T Cells. J Immunol (2020) 204:3227-35. doi: 10.4049/jimmunol.1901276

35. Dickgreber N, Farrand KJ, van Panhuys N, Knight DA, McKee SJ, Chong ML, et al. Immature Murine NKT Cells Pass Through a Stage of Developmentally Programmed Innate IL-4 Secretion. J Leukoc Biol (2012) 92:999-1009. doi: $10.1189 / \mathrm{jlb} .0512242$

36. Park JY, Jo Y, Ko E, Luckey MA, Park YK, Park SH, et al. Soluble Gamma c Cytokine Receptor Suppresses IL-15 Signaling and Impairs iNKT Cell Development in the Thymus. Sci Rep (2016) 6:36962. doi: 10.1038/srep36962

37. Kennedy MK, Glaccum M, Brown SN, Butz EA, Viney JL, Embers M, et al. Reversible Defects in Natural Killer and Memory CD8 T Cell Lineages in Interleukin 15-Deficient Mice. J Exp Med (2000) 191:771-80. doi: 10.1084/ jem.191.5.771

38. Ranson T, Vosshenrich CA, Corcuff E, Richard O, Muller W, Di Santo JP. IL15 is an Essential Mediator of Peripheral NK-Cell Homeostasis. Blood (2003) 101:4887-93. doi: 10.1182/blood-2002-11-3392

39. Fehniger TA, Suzuki K, Ponnappan A, VanDeusen JB, Cooper MA, Florea SM, et al. Fatal Leukemia in Interleukin 15 Transgenic Mice Follows Early Expansions in Natural Killer and Memory Phenotype CD8+ T Cells. J Exp Med (2001) 193:219-31. doi: 10.1084/jem.193.2.219

40. Spolski R, Li P, Leonard WJ. Biology and Regulation of IL-2: From Molecular Mechanisms to Human Therapy. Nat Rev Immunol (2018) 18:648-59. doi: 10.1038/s41577-018-0046-y

41. Yao Z, Cui Y, Watford WT, Bream JH, Yamaoka K, Hissong BD, et al. Stat5a/B are Essential for Normal Lymphoid Development and Differentiation. Proc Natl Acad Sci USA (2006) 103:1000-5. doi: 10.1073/pnas.0507350103

42. Tuttle KD, Krovi SH, Zhang J, Bedel R, Harmacek L, Peterson LK, et al. TCR Signal Strength Controls Thymic Differentiation of iNKT Cell Subsets. Nat Commun (2018) 9:2650. doi: 10.1038/s41467-018-05026-6

43. Dashtsoodol N, Bortoluzzi S. and Schmidt-Supprian M. T Cell Receptor Expression Timing and Signal Strength in the Functional Differentiation of Invariant Natural Killer T Cells. Front Immunol (2019) 10:841. doi: 10.3389/ fimmu.2019.00841

44. Wang H, Hogquist KA. How Lipid-Specific T Cells Become Effectors: The Differentiation of iNKT Subsets. Front Immunol (2018) 9:1450. doi: 10.3389/ fimmu.2018.01450

45. Kwon DI, Lee YJ. Lineage Differentiation Program of Invariant Natural Killer T Cells. Immune Netw (2017) 17:365-77. doi: 10.4110/in.2017.17.6.365 
46. Lazarevic V, Zullo AJ, Schweitzer MN, Staton TL, Gallo EM, Crabtree GR, et al. The Gene Encoding Early Growth Response 2, a Target of the Transcription Factor NFAT, is Required for the Development and Maturation of Natural Killer T Cells. Nat Immunol (2009) 10:306-13. doi: 10.1038/ni.1696

47. Seiler MP, Mathew R, Liszewski MK, Spooner CJ, Barr K, Meng F, et al. Elevated and Sustained Expression of the Transcription Factors Egr1 and Egr2 Controls NKT Lineage Differentiation in Response to TCR Signaling. Nat Immunol (2012) 13:264-71. doi: 10.1038/ni.2230

48. Park JY, DiPalma DT, Kwon J, Fink J, Park JH. Quantitative Difference in PLZF Protein Expression Determines iNKT Lineage Fate and Controls Innate CD8 T Cell Generation. Cell Rep (2019) 27:2548-57.e4. doi: 10.1016/ j.celrep.2019.05.012

49. Suwa H, Tanaka T, Kitamura F, Shiohara T, Kuida K, Miyasaka M. Dysregulated Expression of the IL-2 Receptor Beta-Chain Abrogates Development of NK Cells and Thy-1+ Dendritic Epidermal Cells in Transgenic Mice. Int Immunol (1995) 7:1441-9. doi: 10.1093/intimm/7.9.1441

50. Sarafova SD, Van Laethem F, Adoro S, Guinter T, Sharrow SO, Feigenbaum L, et al. Upregulation of CD4 Expression During MHC Class II-Specific Positive Selection is Essential for Error-Free Lineage Choice. Immunity (2009) 31:48090. doi: 10.1016/j.immuni.2009.07.006

51. Gioulbasani M, Galaras A, Grammenoudi S, Moulos P, Dent AL, Sigvardsson M, et al. The Transcription Factor BCL-6 Controls Early Development of
Innate-Like T Cells. Nat Immunol (2020) 21:1058-69. doi: 10.1038/s41590020-0737-y

52. Walker SR, Nelson EA, Frank DA. STAT5 Represses BCL6 Expression by Binding to a Regulatory Region Frequently Mutated in Lymphomas. Oncogene (2007) 26:224-33. doi: 10.1038/sj.onc.1209775

53. Johnston RJ, Choi YS, Diamond JA, Yang JA, Crotty S. STAT5 is a Potent Negative Regulator of TFH Cell Differentiation. J Exp Med (2012) 209:243-50. doi: 10.1084/jem.20111174

54. Nurieva RI, Podd A, Chen Y, Alekseev AM, Yu M, Qi X, et al. STAT5 Protein Negatively Regulates T Follicular Helper (Tfh) Cell Generation and Function. J Biol Chem (2012) 287:11234-9. doi: 10.1074/jbc.M111.324046

Conflict of Interest: The authors declare that the research was conducted in the absence of any commercial or financial relationships that could be construed as a potential conflict of interest.

Copyright (๑) 2021 Won, Kim, Crossman, Awasthi, Gress and Park. This is an openaccess article distributed under the terms of the Creative Commons Attribution License (CC BY). The use, distribution or reproduction in other forums is permitted, provided the original author(s) and the copyright owner(s) are credited and that the original publication in this journal is cited, in accordance with accepted academic practice. No use, distribution or reproduction is permitted which does not comply with these terms. 